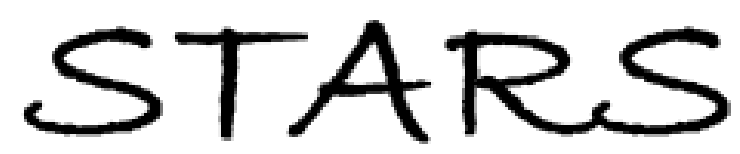

University of Central Florida

STARS

\title{
Cyber Sexy:electronic Game Play And Perceptions Of Attractiveness Among College-aged Men
}

Elizabeth Wack

University of Central Florida

Part of the Psychology Commons

Find similar works at: https://stars.library.ucf.edu/etd

University of Central Florida Libraries http://library.ucf.edu

This Masters Thesis (Open Access) is brought to you for free and open access by STARS. It has been accepted for inclusion in Electronic Theses and Dissertations, 2004-2019 by an authorized administrator of STARS. For more information, please contact STARS@ucf.edu.

\section{STARS Citation}

Wack, Elizabeth, "Cyber Sexy:electronic Game Play And Perceptions Of Attractiveness Among Collegeaged Men" (2007). Electronic Theses and Dissertations, 2004-2019. 3398.

https://stars.library.ucf.edu/etd/3398

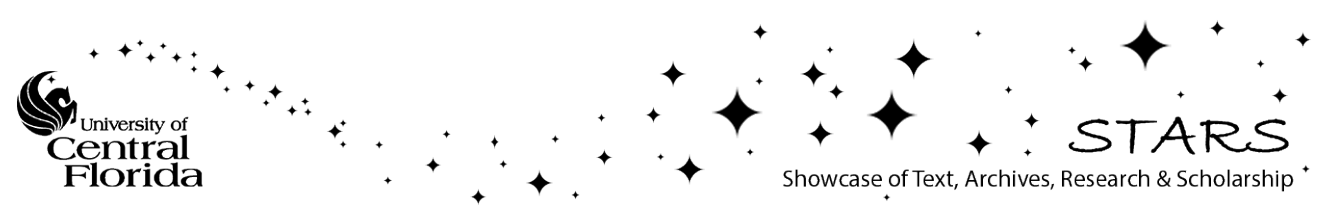




\title{
CYBER SEXY: ELECTRONIC GAME PLAY AND PERCEPTIONS OF ATTRACTIVENESS AMONG COLLEGE-AGED MEN
}

by

\section{ELIZABETH RUTH WACK}

B.S. University of Florida, 2005

\author{
A thesis submitted in partial fulfillment of the requirements \\ for the degree of Master of Science \\ in the Department of Psychology \\ in the College of Sciences \\ at the University of Central Florida \\ Orlando, Florida
}

Spring Term

2007

Major Professor: Stacey Tantleff Dunn 


\begin{abstract}
The current study was conducted to determine whether or not electronic gaming is related to the formation of certain body ideals and appraisals of attractiveness. A sample of 219 collegeaged males (age 18 to 32) completed a variety of measures designed to gather information about their game play habits, their perceptions of their own attractiveness (MBSRQ, SMAQ), and their perceptions of women's attractiveness (BCRS, FRS, photographs of women of different BMIs). Results indicate that men's ratings of women's attractiveness vary across the genres of games most frequently played but that frequency of play and age of commencement of game play are not related to self-perceptions of physical attractiveness, the association of positive attributes with muscularity, or the drive to become more muscular. However, results suggest that men's appearance satisfaction and the degree to which they value muscularity are influenced by the extent to which they compare their own appearance to that of the characters they play in the games. Results indicate that unlike other forms of media, electronic gaming is not related to decreased appearance satisfaction in players or the formation of unrealistic standards of attractiveness for women.
\end{abstract}


To Laurie, Rick, and Justine, for their patience. To Diana, for making me laugh. And to Rick Mottola for all his hard work! 


\section{TABLE OF CONTENTS}

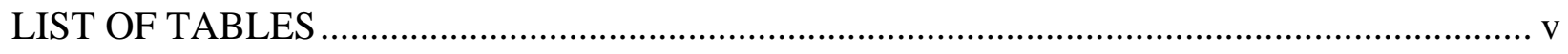

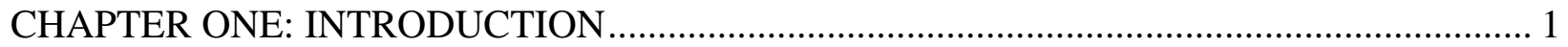

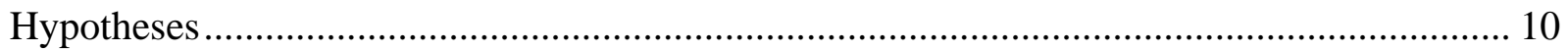

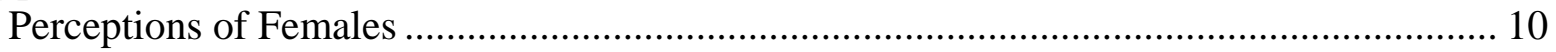

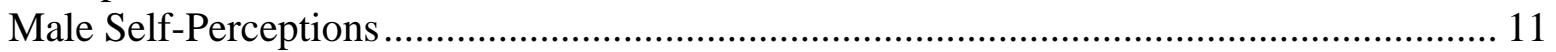

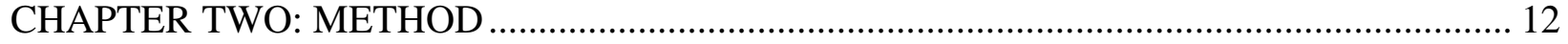

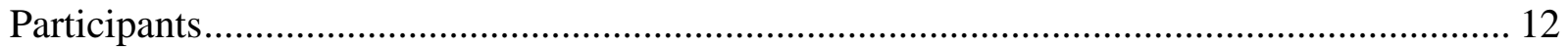

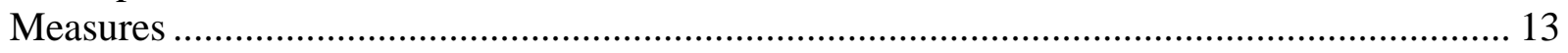

Demographic Questionnaire (see Appendix A) .......................................................... 13

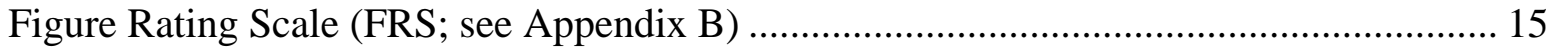

Breast/Chest Rating Scale (BCRS; see Appendix C) ................................................... 15

Photographs of college-aged females (see Appendix D) .............................................. 16

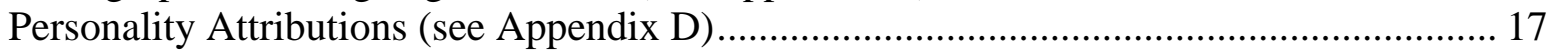

Swansea Muscularity Attitudes Questionnaire (SMAQ) (Appendix E) .............................. 17

Multidimensional Body-Self Relations Questionnaire (MBSRQ) (Appendix F)................ 17

Sociocultural Attitudes Towards Appearance Questionnaire (SATAQ-3)(Appendix G) .... 18

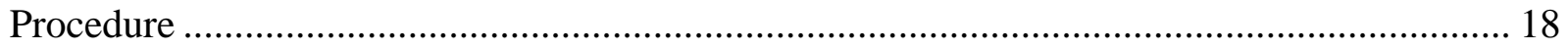

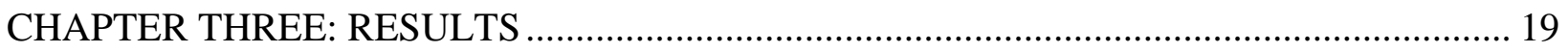

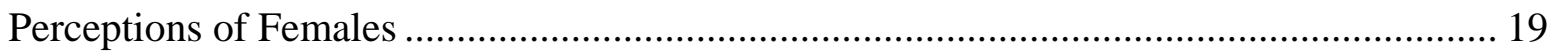

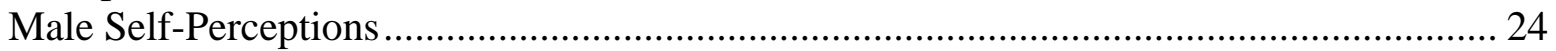

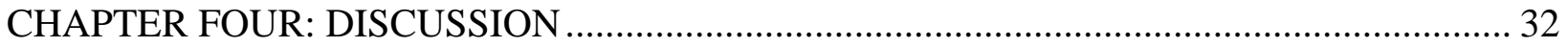

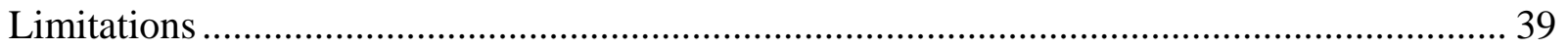

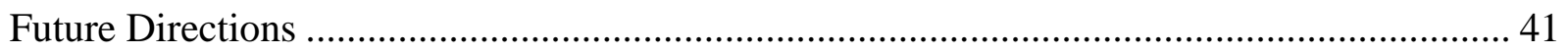

APPENDIX A: DEMOGRAPHIC QUESTIONNAIRE WITH TIMELINE FOLLOW-BACK

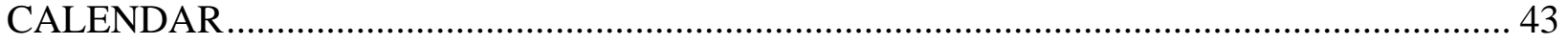

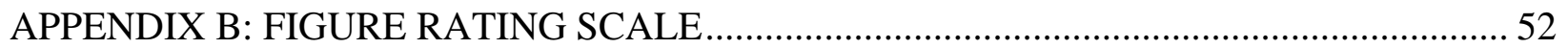

APPENDIX C: BREAST/CHEST RATING SCALE ....................................................... 54

APPENDIX D: PHOTOGRAPHS OF COLLEGE-AGED FEMALES AND PERSONALITY

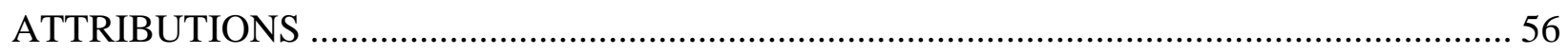

APPENDIX E: SWANSEA MUSCULARITY ATTITUDES QUESTIONNAIRE ................... 67

APPENDIX F: MULTIDIMENSIONAL BODY-SELF RELATIONS QUESTIONNAIRE...... 70 APPENDIX G: SOCIOCULTURAL ATTITUDES TOWARDS APPEARANCE

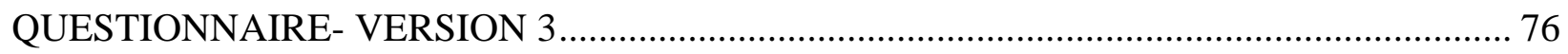

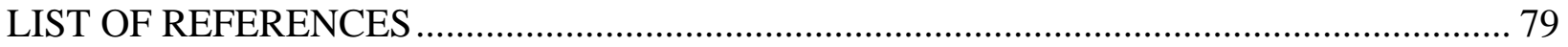




\section{LIST OF TABLES}

Table 1 Mean Ratings of Attractiveness and Standard Deviations for Women from BMI Categories by Players of Electronic Games........................................................................ 27

Table 2 Mean Ratings of Attractiveness for Women from BMI Categories by Players of

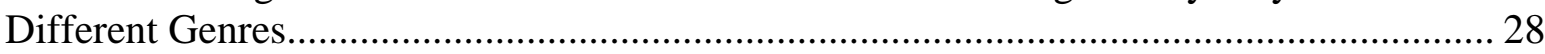

Table 3 Mean Selection of Most Attractive Breast Size from the Breast/Chest Rating Scale by Players of Different Genres ........................................................................................ 29

Table 4 Correlations between Attributions of Desirable Personality Characteristics for Women within Each BMI Classification and Frequency of Play ...................................................... 30

Table 5 Percentages of Players who Indicated Majority of Play Within Each Genre and Mean Hours of Play Reported Over a Three-Day Period for Each Genre........................................ 31 


\section{CHAPTER ONE: INTRODUCTION}

The effect of media exposure on psychological and cognitive functioning has been a popular avenue of research for the past few decades as studies have found that Americans, especially young Americans, are increasingly voracious consumers of media. As of 1999, 30\% of the U.S. toy market was comprised of video games, which helped the video game industry to earn between $\$ 6$ billion and $\$ 9$ billion, outselling even the motion picture industry (Jenkin, 2000; Dickinson, 2000). A 2004 estimate of media consumption by the Kaiser Family Foundation suggests that the typical American youth between 8 and 18 years of age, spends $6 \mathrm{hr}$ and $47 \mathrm{~min}$ per day with electronic media and 43 min per day with print media (Rideout, Roberts, \& Foehr, 2005). Television remains the primary source of media exposure, with the average child watching $3 \mathrm{hr}$ and 51 min per day. Yet, video game play and non-school related computer access occupies $1 \mathrm{hr}$ and 52 mins of a typical child's day.

The same report reveals that sheer access to electronic media in the home is on the rise: $83 \%$ of young people (between ages 8 and 18) have a video game console at home, and $49 \%$ of those children have a video game player in their own bedroom and 31\% have a computer in their own bedroom. However, a gender discrepancy exists as more boys have a video game console ( $63 \%$ vs. $33 \%$ ) or computer (35\% vs. $26 \%$ ) in their rooms than girls. Electronic game play has been found to decrease with age from elementary to high school; for instance, in a study by Buchman and Funk (1996), fourth grade boys reported playing electronic games for about $9 \mathrm{hr}$ 30 min per week while eighth grade boys reported playing for about 5 hr per week. Although electronic game play reportedly decreases throughout the first 17 to 18 years of life, the average 
college aged male reportedly plays electronic games approximately 15 hr per week, as found by a study as part of the 2003 Pew Internet and American Life Project (however, variations in this figure exist). Additionally, the study found that $65 \%$ of college students reported being regular or occasional game players.

With these statistics in mind, it is hard to deny the tremendous integration of media, especially electronic media, into the everyday life of an American youth. The implications of this availability are far-reaching and have been found to influence both behavior and lifestyle. It is well known that increased television watching has many deleterious correlations including decreases in school achievement (Huston et al., 1992), increases in obesity (Robinson, 1999), and increases in aggression (Donnerstein, Slaby, \& Eron, 1994). A study by Dorr and Rabin (1995) suggests that viewing typical television programming teaches more sexist and aggressive attitudes. Findings related to extended media usage indicate extensive negative outcomes for children and adolescents, dependent upon the content and amount of exposure, within academic, interpersonal, and family settings (Gentile \& Walsh, 2002).

The effect of continued exposure to media violence is a main concern accompanying the current elevated levels of media consumption. Donnerstein and colleagues (1994) found that media with a high content of violence leads to an increase in aggression, desensitization, fear, and desire for more media depicting violence. Furthermore, a diverse base of research with a variety of methods, samples, time frames and media stimuli has found that media violence is a significant contributory factor in violence among young people and that repeated or even brief exposure to violence in television shows or in movies causes significant increases in aggressive behavior (Bushman \& Huesman, 2001; Anderson et al., 2003). 
Results concerning the relationship between exposure to media violence and real-life factors transcend television and have been found in research on video games (Anderson et al., 2003). Video and computer games in particular are an increasingly available and enticing form of media that is studied much less frequently than television. However, similar conclusions regarding exposure to violence on television have been reached for violence in video games. A meta-analytic review of the scientific literature on exposure to violence in video games examined its influence on human behavior and cognition across 35 research reports (Anderson \& Bushman, 2001). Results across the 4,262 participants revealed that video game violence was associated with heightened aggression, a temporary decrease in prosocial behavior, increased aggressive thoughts, increased aggressive affect, and increased physiological arousal.

Further evidence for the relationship between violent video game play and aggressive behavior was suggested by the results of a correlational study by Anderson and Dill (2000), which found that realistically violent video game play was positively related to increased delinquency and aggressive behavior, especially among characteristically aggressive individuals and men. An experimental component of the same study randomly assigned college-aged men and women to play either a violent or non-violent video game. Following the game play, the participants were asked to indicate any feelings of hostility and irritability. The study revealed that participants who had an extended history of violent video game play had engaged in more aggressive behavior throughout their lives and, that after even brief exposure to violent video games, participants exhibited markedly increased aggressive behavior. Additionally, the results of the study suggest that although men have a more hostile view of the world, the playing of violent video games increase aggression in both male and female participants. Additionally, this 
study and others (e.g. Kestenbaum \& Weinstein, 1985) suggest that violent video game play has both immediate (short-term) and delayed (long-term) effects on players' behavior and cognitions. Reasons underlying the relationship between video game violence and increases in aggression are thought to be similar to those mechanisms found with television violence; playing and watching the games engages the user in learning, rehearsal, and reinforcement of aggressionrelated knowledge structures (as hypothesized in the General Affective Aggression Model) that leads to aggressive beliefs, attitudes, schematas, behavior scripts, as well as arousal and overall behavior desensitization (Anderson \& Bushman, 2001; Anderson et al., 2003). The learning about and rehearsal of aggressive behavior usually begins with playing electronic games in childhood but even a few exposures later in life has been found to be positively related to increases in aggression (Anderson \& Dill, 2000).

Evidently, a powerful relationship exists between the repetitious rehearsal of aggressive thoughts and attitudes provoked by violent electronic game play. If this relationship between the fantasy worlds of computer and video games exists within the context of violence and aggression, what other influences might video games have on spheres of human perception and behavior? The current study investigated whether a similar impact exists within the realm of body image as is purported within the literature examining electronic games and violence. The current study examined the effect of electronic game play on perceptions and standards of attractiveness among male college students, who make up a significant percentage of electronic game players.

Not surprisingly, mass media has been implicated in affecting human cognition and behavior beyond the realms of violence and aggressive behavior. Rather than the viewer 
internalizing aggressive and violent schemas from exposure to mass media, the sociocultural theory of body image dissatisfaction purports that the images of idealized bodies to which people are continuously exposed in mass media, often lead to the internalization and adoption of unhealthy standards of attractiveness. The research supporting this theory suggests that exposure to unrealistic body ideals through the media and the extent to which an individual internalizes those ideals and values, negatively influences the individual's appraisal of his or her own body (Stice, Schupak-Neuberg, Shaw, \& Stein, 1994; Thompson \& Stice, 2001). The implications of this theory are far reaching and are purported to affect men (Agliata \& Tantleff-Dunn, 2004), women (Thompson \& Stice, 2001), children (Dittmar, Halliwell, \& Ive, 2003) and adolescents (Groesz, Levine, \& Murnen, 2002). A study by Dittmar, Halliwell, and Ive (2003) suggested that the mechanisms underlying sociocultural theory begin at a very young age. The study found that 5- and 6-year old girls reported an increased desire for a thinner body and lowered self-esteem after viewing images of a Barbie doll. Evidently, the media- whether televison, magazine, toy or any other easily accessible vehicle of American society’s body ideals- can act as a powerful communicator of what is considered attractive for women and men.

Video games involving female characters have been found to depict the female body in an unrealistic and often almost pornographic manner. Following a content analysis, Dietz (1998) found that out of the 33 Nintendo and Sega games examined, $28 \%$ of the female characters were portrayed as sex objects, with large breasts and thin waist. In a more recent content analysis examining 597 characters from 47 randomly selected games, Beasley and Collins Standley (2002) found that $41 \%$ of all female characters in their analysis were big busted and wearing clothes to emphasize their sexuality. Furthermore, 31\% of the voluptuous and scantily clad 
women appeared in games rated E, or suitable for everyone. Researchers hypothesize that this portrayal is designed to attract men and is in line with research on standards of attractiveness for women (Dietz, 1998).

Several objective measures of female attractiveness are useful in gauging how images in electronic games are designed to emphasize female sexuality and attractiveness, particularly waist-to-hip ratio and body mass index. The waist-to-hip ratio (WHR) has been found to be an important general predictor of ratings of physical attractiveness and other related characteristics (Brase \& Walker, 2004). This is hypothesized to be due to an adaptive theory regarding mate selection in which a curvaceous body is an indicator of many positive female characteristics, among them: high fertility, youthfulness, and lack of health problems (Wass, Waldenstrom, Rossner, \& Hellberg, 1997; Bjorntorp, 1998, 1991). An abundance of studies by Singh and colleagues reveal that a lower WHR is considered more attractive than a higher WHR, indicating good health and reproductive potential. Interestingly, even female fashion models with low WHR (between 0.68 and 0.72 ) are rated by males as more attractive than fashion models with higher WHR (greater than .72) (Singh 1993a, 1993b, 1994a, 1994b; Singh \& Luis, 1995).

However, WHR is not the only objective measure used to investigate differences in ratings of attractiveness. Body mass index (BMI), a measure of weight scaled for height, and shape have been found to significantly affect men's ratings of attractiveness in studies using figure-line drawings and in studies utilizing pictures of real women (Tovee \& Cornelissen, 2001; Furnham, Tan, \& McManus, 1997). The World Health Organization has suggested that BMI be organized into the following four categories based on BMI calculations: underweight, normal weight, overweight, and obese (WHO, 1997). It has been suggested that BMI, more so than 
weight, shape or WHR, is the most important factor in ratings of attractiveness by men and women (Tovee, Reinhardt, Emery, \& Conelissen, 1998; Tovee, Maisey, Emery, \& Cornelissen, 1999).

Dietz (1998) proposed that exaggeratedly proportioned portrayals of women within video games are created to cater to the mostly male population of electronic game players, thus incorporating the standards of attractiveness discussed above, including a highly exaggerated WHR. However, standards of attractiveness can be impacted by exposure to certain images. For instance, a classic study by Kenrick and Gutierres (1980) examined the impact of watching a television show featuring three strikingly attractive women as main characters on men's ratings of the attractiveness of a "normal” woman after watching the show. Results uncovered a “contrast effect,” wherein men who had viewed the women on television rated the average woman as less attractive than did men who had not viewed the attractive women prior to rating the average woman. An extension of the contrast effect theory was applied to a study of sexual attraction in which men and women were exposed to a photograph of an average (non-model) nude woman after exposure to either a nude centerfold from popular erotica, or to a photograph of abstract art or another average nude woman (Kenrick, Gutierres, \& Goldberg, 1989). Results indicated that both males and females judged the target as less attractive after being exposed to the centerfold from popular erotica.

Although the contrast effect has been shown to exist with certain types of mass media (television and magazines), it has not yet been tested when examining it in the context of electronic games. The current study strives to combine two of the theoretical points described above in the context of body image: first, that the repetitious rehearsal and learning required of a 
user while playing video games may cause the user to internalize unrealistic depictions of female attractiveness after playing games featuring non-normal, WHR exagerated female figures and secondly, that exposure to unrealistically portrayed female game characters will affect users’ ratings of attractiveness for real women. Not unlike research involving video games and aggression, this study will examine users’ perceptions of attractiveness to investigate a possible relationship resulting from the contrast effect and sociocultural theory. The extrapolation of the concepts used in investigating exposure to video game violence and aggression to the realm of body image is not unfounded. The research clearly delineates a connection between exposure to violence, brief or long term, and increases in aggressive behaviors, attitude and affect as well as decreases in prosocial behaviors, attitudes and affect (Anderson \& Bushman, 2001). With such powerful connections within this domain, it is possible that similar connections can be made between repeated exposure to unrealistic depictions of female bodies and perceptions of real women.

In addition to investigating whether electronic game play affects men's perceptions of women’s attractiveness, the current study investigated whether a relationship exists between frequency and genre of electronic game play and men’s body image, perceptions of male attractiveness, and body ideals for men. Most content analyses have focused mainly on the depiction of the female characters, concluding that they are routinely portrayed in a provocative and sexually suggestive manner (Beasley \& Collins Standley, 2002; Dietz, 1998). However, these same content analyses have found that electronic games contain more male characters than female characters (Ivory, 2006). If these games contain more male characters than female, why has research focused primarily on the minority female characters? It is important to note that 
women are not the only characters in electronic games that are portrayed with unrealistic physiques. A study by Scharrer (2004) found that male characters are routinely depicted with exaggerated muscularity, presenting an ideal body that may be impossible to attain. This finding invokes an important question: How do the hyper masculine, hyper muscular depictions of male bodies in electronic games affect the way that male players view themselves? Agliata and Tantleff-Dunn (2004) found that exposure to ideal male images in the media increased levels of depression and muscle dissatisfaction among college-aged men. Furthermore, the social comparison theory suggests that people judge themselves largely in comparison to others, which can clearly result in further body image dissatisfaction when the model used during the comparison is highly idealized and practically unattainable (Festinger, 1954). A national survey conducted in 1997 found that males experienced rising levels of body dissatisfaction, from 15\% to 43\% (Cash, 1997). However, for the most part, research on males’ body image has generally been overshadowed by a focus on females' body image concerns.

An additional avenue that warrants exploration within this domain is the effect of physical appearance on opinion formation. A variety of attributions about personality factors are made based solely on appearance and it is important to understand both the extent and nature of these attributions. A study by Tantleff-Dunn (2002) found that breast size influenced the degree to which males positively rated women on professional and social characteristics. This study investigated the degree to which college aged males attribute certain personality characteristics to women of different BMI and WHR and whether or not these attributions are related to frequency of electronic game play. 
In summary, previous literature suggests that media exposure is related to the formation of deleterious attitudes and implies that there is an important link between violent video game play and certain behavioral outcomes and resulting attitudes. The tragedy at Columbine High School is frequently referred to in research on this topic and although the implications that video and electronic game play could have in the domain of body image are less destructive and life threatening, they could potentially change the unspoken standards society relies upon to make judgments. Electronic game play potentially could change the perceptions of attractiveness for men and women and cause significant changes in the way people are expected to behave and look, potentially resulting in deleterious psychological consequences like depression and eating disorders. The issue at the core of this study is the possible extension of unrealistic standards internalized during continuous and repetitious exposure to idealized female and male characters in electronic games to actual women and men. In particular, the focus is on isolating particular variables (such as frequency, age of commencement of play, and genre of play) that may contribute to the development of potentially harmful and stereotyped attitudes regarding attractiveness.

\section{$\underline{\text { Hypotheses }}$}

\section{Perceptions of Females}

It was hypothesized that:

1. Frequency of electronic game play will be negatively correlated with ratings of attractiveness for photographs of normal weight (BMI between 18.5 and 24.9) college aged females. Players of electronic games will rate normal weight women as less attractive than underweight (BMI below 18.5) women. 
2. Frequency of electronic game play will be positively correlated with the size of the "most attractive breast size" selected from the Breast/Chest Rating Scale.

3. There will be differences in the ratings of women from the four separate BMI classifications depending on the genre of game most frequently played. There will be differences in the selection of a "most attractive breast size" depending on the genre of game most frequently played.

4. The photographs of the normal weight college aged females will be rated as less attractive by players who began playing video games at a younger age. Additionally, players who began playing electronic games at a younger age will select larger breasts as most attractive on the Breast/Chest Rating Scale compared to players who began playing later in life.

5. Frequency of electronic game play will be negatively correlated with ratings of desirable personality attributes (i.e., intelligence, athleticism, confidence) for normal weight, overweight, and obese women and positively correlated for underweight women.

\section{Male Self-Perceptions}

It was hypothesized that:

1. The frequency of electronic game play will be negatively correlated with appearance satisfaction as measured by the MBSRQ and positively correlated with the association of positive (masculinity, partner attractiveness, maturity, etc.) traits with muscularity (measured by the SMAQ). 
2. The age at which electronic game play began will be positively correlated with appearance satisfaction (measured by the MBSRQ) and negatively correlated with the association of positive traits with muscularity (measured by the SMAQ).

3. The degree to which the player compares his physical appearance with game characters will be positively correlated with the association of positive traits with muscularity (measured by the SMAQ) and negatively correlated with appearance satisfaction (measured by the MBSRQ).

4. Players who most frequently play fantasy role playing games will be less satisfied with their appearance (measured by the MBSRQ) and will make a stronger association of positive traits with muscularity (measured by the SMAQ) than players who more frequently play other game genres.

\section{CHAPTER TWO: METHOD}

\section{$\underline{\text { Participants }}$}

The 219 participants were mainly male undergraduates from two academic institutions in the Southeast. The demographics of the sample (age and race) correspond closely to the enrollment profiles of the institutions that participated. The age range of respondents was 18 32, and the mean age was 20.48 years $(S D=2.6)$. The majority $(70.7 \%)$ of the sample was between 18 and 21 years. The sample was comprised of 73.5\% White respondents, 5.9\% Black, 11.0\% Hispanic, 4.6\% Asian, 2.3\% Biracial, and 2.7\% identifying as "other.” The mean age for 
commencement of electronic game play was between seven and eight years of age. Participants self-reported playing electronic games frequently, with $92.7 \%$ of participants reporting they had played electronic games within the last month and $62.1 \%$ reporting they played electronic games within 24 hours of participating in the study.

Participants were asked to estimate the approximate number of hours they currently spend playing electronic games (video or computer) per week. The sample mean of their selfreported approximations was 3.07 hours per week. However, when asked to recall and record their electronic game play time over the previous three days with the use of a timeline followback procedure, the mean number of hours for this significantly smaller time frame was 4.17 , extrapolated to a weekly average of about 9.73 hours. Additionally, $8.5 \%$ of the sample reported playing over 15 hours of electronic games in the three-day period measured with the timeline follow-back procedure. Assuming game play frequency remains consistent throughout the week, these players are spending an average of 35 hours per week on electronic games (see Table 5 for exact percentages and average hours of play for the three-day reporting period).

\section{$\underline{\text { Measures }}$}

Demographic Questionnaire (see Appendix A)

The purpose of this questionnaire was to gather information about the participant demographics in order to describe the sample and establish generalizability of findings. Participants were asked to indicate their age, ethnicity, year in school, approximate grade point average, and other demographic information. An item asking players to indicate how frequently they compared their physiques with those of the characters in the games, measured on a five point Likert scale (1:

Never, 5: Always), was included in this questionnaire as well. In addition, several questions were 
posed in order to determine participants’ game-playing habits, including a self-report of estimated number of hours of game play per week. In addition, a specialized procedure called the timeline follow-back technique (developed to measure alcohol consumption and adapted for the purposes of this study) (Sobell \& Sobell, 1992), was utilized to more accurately determine game playing habits throughout the past week. For the sake of time, although at the cost of accuracy, it was decided that the timeline follow-back would account for the last three-days of game play rather than the last seven-days, with a mean weekly frequency extrapolated from the three-day mean. Due to a significant difference between the self-report item used to assess estimated weekly game play frequency and the weekly frequency drawn from the timeline follow-back procedure, the timeline follow-back method of reporting game play was considered to be the more accurate assessment of game play frequency as it entails the recounting of more exact information rather than a general estimation of hours, thereby diminishing the impact of any responding bias. Thus, the three-day frequency total drawn from this measure was used exclusively in any analyses examining the influence of "frequency" on the dependent variables.

In addition to measuring game play frequency, the timeline follow-back procedure was used to group participants based on the genre of electronic game they most frequently played, either first person shooter, fantasy role-playing (a genre that consists of characters with particularly exaggerated physical proportions), action, sports, racing, fighting or miscellaneous (if a game could not be grouped as a particular genre, for instance, if it included elements of several genres). All participants who endorsed current game play were grouped into these categories based on the percentage of time spent playing the particular genre during the three-day period tracked by the timeline follow-back procedure. As part of the procedure, respondents are 
prompted to provide the name of each game played during each period of time. The games themselves were pre-coded as members of particular genres based on particular storyline features researched through that particular game manufacturer's website. Participants had to endorse involvement in a particular genre for over $75 \%$ of overall game play to be grouped as players of the particular genre. Every participant met criteria to be grouped as a player of a particular genre (see Table 5). No participant played two different genres for an amount of time that would warrant their classification as a player of two or more genres.

Figure Rating Scale (FRS; see Appendix B)

To assess perceptions of attractiveness, undergraduate males selected a "most attractive” female figure or "ideal” male figure from the Figure Rating Scale. The Figure Rating Scale is composed of nine figures of increasing size with accompanying numerical ratings from 1 to 9. Participants were asked to select the figure that they find most attractive as well as the figure that they believe is preferred by most women and most men. Additionally, participants were asked to indicate the male figure they feel to be ideal as well as the male figure they believe most women prefer and most men prefer in order to perform exploratory analyses in the realm of male body image. Testretest reliability in a sample of 34 undergraduate males (ages 17- 25) for a 2-week interval was found to be .76 for males' ratings of most attractive female figure and .82 for males' ratings of the ideal male figure (Thompson \& Altabe, 1991).

\section{Breast/Chest Rating Scale (BCRS; see Appendix C)}

To assess perceptions of breast and chest size, undergraduate males were asked to select between five drawn female figures with varying breast sizes and five drawn male figures with varying 
chest sizes (Thompson \& Tantleff, 1992). The Breast/Chest Rating Scale is similar to the Figure Rating Scale in that it is comprised of drawn figures, however the variation between the figures is the increasing breast size on female figures or increasing chest size on male figures and no other dimensions are altered. Participants were prompted to select the figure with the breast size they felt was the most attractive or ideal, as well as the female figure with the breast size they believed other men prefer and the figure they think most women prefer. Additionally, they selected the male chest size they found to be ideal and the chest size they believe most other men and women prefer. The BCRS has acceptable psychometric properties for both breast and chest ratings (Thompson, Heinberg, Altabe, \& Tantleff-Dunn, 1999). Test-retest reliability was .81 for the "Breast-Ideal”, the breast size considered ideal by male raters. Test-retest reliability was .69 for the "Chest-Ideal”, the chest size considered ideal by male raters. Additionally, to control for order effects, the FRS and the BCRS were presented to the participants in random order.

\section{Photographs of college-aged females (see Appendix D)}

To further gauge perceptions of attractiveness, photographs of female undergraduate bodies (previously rated by men in a pilot study in order to assure a range of attractiveness) were rated for attractiveness on a scale of 1 (least attractive) to 10 (most attractive). The women in the photographs appeared in the same shorts and t-shirts against the same backdrop in order to minimize the impact of additional variables that could account for variance in ratings. In order to assure participant focus on the body and to protect identities, the faces of the women were blurred. The women represented a variety of body shapes and races (White, Black, AsianAmerican, and Hispanic) but to minimize the influence of skin tone, the pictures were reproduced in black and white. Therefore, it is believed that this measure adequately captures the 
construct of interest: body shape and proportion. To control for order effects, the photographs appeared in random order throughout the questionnaire.

\section{Personality Attributions (see Appendix D)}

Participants completed questions regarding their estimation of certain personality characteristics for the women in the photographs. Participants were asked to indicate on a fourpoint Likert scale (1: not at all, 2: somewhat, 3: above average, 4: extremely) the degree to which each woman in the photographs possesses a particular personality trait, for instance, intelligence, loneliness, confidence, or sociability.

\section{Swansea Muscularity Attitudes Questionnaire (SMAQ) (Appendix E)}

This measure was used to assess the importance of muscularity and the meaning of muscularity in participants' lives. The SMAQ consists of 20 items that load onto two factors measuring males' drive towards muscularity (Cronbach's alpha .94) and the positive attributes associated with muscular physiques, such as increased confidence, feelings of attractiveness, and overall competence ( $r$ = .91; Edwards \& Launder, 2000).

\section{Multidimensional Body-Self Relations Questionnaire (MBSRQ) (Appendix F)}

This measure was used to assess the participants' feelings of attractiveness and the importance of appearance in their life, as well as feelings of being physically fit and their overall investment in fitness (Cash, Winstead, \& Janda, 1985). The highly-validated MBSRQ is widely used in body image research and has high internal consistency and test-retest reliability (Cash, Winstead, \& Janda, 1986). The primary factor used in the assessment of the hypotheses for this study is the Appearance Evaluation factor (MBSRQ-AE), which can be found to be either high 
(indicating more positive feelings about and satisfaction with appearance) or low (indicating more negative feelings about and dissatisfaction with appearance) based on general population norms.

\section{Sociocultural Attitudes Towards Appearance Questionnaire (SATAQ-3)(Appendix G)}

This measure was used to assess the degree to which participants' body images are affected by societal influences. This 30-item measure, consisting of an Awareness and Internalization subscale, was used to gauge the degree of societal influence, through media sources and athletic figures, on participants' body image. The measure has excellent convergent validity with other measures of body image while uniquely gauging several deep dimensions of media influence. For instance, there is a moderate correlation between the Internalization subscale $(r=-.28)$ and the MBSRQ-AE, as well as between the Awareness subscale $(r=-.42)$ and the MBSRQ-AE. The correlation between the two subscales is .34 (Heinberg, Thompson, \& Stormer, 1995; Thompson, Van den Berg, Roehrig, Guarda, \& Heinberg, 2004).

\section{Procedure}

Students attending several academic institutions in the Southeast were recruited were recruited via email to complete the online survey. Students completed the online survey through a survey hosting service called Zoomerang. Students electronically signed an informed consent form available through the Zoomerang website, completed the packet, received a debriefing form that they could print for their records, and were given the opportunity to receive results from the study. 


\section{CHAPTER THREE: RESULTS}

The analyses were conducted with SPSS for Windows version 14.0 (SPSS, 2005) using an alpha level of .05, unless otherwise noted. All data were screened for violations of the assumption of normality, skewedness and kurtosis, for outliers, and for independence of errors. Descriptive statistics and additional correlations beyond the hypotheses were calculated to provide additional information about participant demographics and their relationship to the study variables.

\section{Perceptions of Females}

\section{Hypothesis One}

The relationship between self-reported number of hours spent playing electronic games per week and ratings of attractiveness for photographs of normal weight college-aged females was significant $(r=.191, p<.01)$, indicating that more frequent electronic game play was associated with higher ratings of attractiveness of normal weight females. This finding was contradictory to the negative correlation hypothesized in that the more frequently participants played electronic games, the more favorably they rated normal weight women. There were no significant correlations between frequency of electronic game play and ratings of attractiveness for photographs of underweight, overweight or obese college-aged females

In addition, paired samples t-tests comparing the mean ratings for each BMI category were conducted for participants who endorsed that they are current game players $(n=126)$. Controlling for familywise error rate across the six tests at the .05 level, using Holm's sequential Bonferroni procedure, all of the comparisons between mean ratings for each of the BMI 
classifications were significant, except for a comparison of mean ratings for underweight and obese women, indicating that participants rated underweight and obese women as equally unattractive. Table 1 shows the overall mean ratings and standard deviations for ratings of women from each BMI classification. This result suggests that players of electronic games rate normal weight women as significantly more attractive than underweight women, contradicting the hypothesis that players would find normal body types as less attractive than the thinner ideal portrayed in electronic games.

\section{Hypothesis Two}

The proposed relationship between self-reported number of hours spent playing electronic games per week and the figure selected from the Breast/Chest Rating Scale to have the "most attractive breast size" was not significant $(r=-.07, p=.33)$. This indicates that there is no relationship between the number of hours of games played per week and participants' concept of the ideal breast size.

\section{Hypothesis Three}

A multivariate analysis of variance (MANOVA) was used to determine if there was a significant interaction between genre of game most frequently played and BMI classification for attractiveness ratings of the women in the photographs. The interaction approached significance, $F(18,357)=.1 .58, p=.07$. Given the exploratory nature of the study, this multivariate effect was further examined with a one-way repeated measures analysis of variance.

The interaction of BMI and genre was significant, $F(18,357)=1.84, p<.05$. Post-hoc tests (LSD) indicated that several significant mean differences in ratings of attractiveness existed across genres. Although on the whole, mean ratings of attractiveness for underweight women 
were significantly lower than the mean ratings of attractiveness for normal weight and overweight women, players of fantasy role-playing and action games rated underweight women as significantly more attractive than players of other genres, while players of first person shooter games rated underweight women to be significantly less attractive than players of other genres. Table 2 summarizes these post-hoc findings.

An additional ANOVA examining the most attractive breast size selection revealed a significant main effect for genre for the whole sample, $F(6,357)=2.62, p<.05$, as well as for a smaller sample consisting of only active game players, $F(6,133)=2.17, p<.05$. Post-hoc (LSD) tests revealed that there were significant mean differences in selections of most attractive breast size between players of almost every genre of electronic games (see Table 3). For instance, players of racing and sports games selected significantly larger breast sizes than players of fighting and first person shooter games.

\section{Hypothesis Four}

To test the proposed relationship between age of commencement of electronic game play and the ratings of attractiveness for photographs of normal weight women or the selection of most attractive breast size from the Breast/Chest Rating Scale, a multiple correlation analysis was conducted. There were no significant correlations between the age at which electronic game play began and the ratings of attractiveness for photographs of normal weight women or for photographs of women that fall within the underweight, overweight or obese categories. Furthermore, the selection of most attractive breast size from the Breast/Chest Rating Scale was not significant $(r=.02, p=.79)$. 


\section{Hypothesis Five}

A personality attribution score was calculated based on the attributions participants made for each woman's photograph. A mean score was calculated from each participant's rating of photographs within a particular BMI classification. For instance, each participant rated the four female photographs representing normal BMI on each personality dimension. The mean personality score for normal weight women was created by averaging the ratings for favorable and unfavorable personality characteristics given by each participant for each of the different photographs. Thus, each participant had a personality attribution score for each BMI classification.

A multiple correlation analysis was conducted to test the relationship between the personality attribution scores for each BMI classification and the frequency of electronic game play. The proposed relationship between frequency of electronic game play and attributions of desirable personality characteristics to thinner women was not significant $(r=.08, p=.27)$. There also was no significant relationship between frequency of play and attributions of either favorable or unfavorable personality characteristics to photographs of women from any particular BMI classification (see Table 4).

In an effort to examine whether any significant differences in ratings of attractiveness existed for any particular woman featured in the photographs and rule out the possibility that a particular body was decreasing the power of the analyses to detect differences in average ratings of the BMI categories, separate ANOVAs were performed for each photograph for each variable of interest. No significant differences were found, indicating that the ratings for each woman were consistent across the sample. 


\section{Exploratory Multiple Regressions}

In order to investigate whether a predictive relationship exists for frequency of play and age of commencement of electronic game play for the perceptions of attractiveness men have for women, two multiple regression analyses using simultaneous entry were conducted. In the first analysis, the criterion variable was the participants' ratings of attractiveness of the photographs of normal weight women (BMI between 18.5 and 24.9). The predictor variables were the starting age of electronic game play and hours of electronic game play over a three-day period based on the timeline follow-back (found to be the more accurate measure of game play frequency). The regression equation was not significant for any of the BMI classifications.

In order to exclude the possibility that the ratings of non game-players (those who reported playing zero hours of games per week) were interfering with the main construct of interest (the influence of current game play), "non-players” were excluded and the data was reanalyzed $(n=126)$. The regression equation for this "player" sample was non-significant.

The same multiple regression analysis was conducted for the full sample (including both players and non-players) with participants' selection of the "most attractive breast" from the Breast/Chest Rating Scale as the criterion variable. The predictor variables were the same: starting age of electronic game play and hours of electronic game play over a three-day period. Neither the regression equation nor the any of the predictor variables independently were significant. Even with non-players once again removed from the sample, the regression equation was not significant for this set of predictor variables, indicating that there is no significant predictive relationship between the age electronic game play began and the current frequency of that play for the selection of a most attractive breast size. 


\section{Male Self-Perceptions}

\section{Hypothesis One}

The correlation between frequency of electronic game play and self-report ratings of overall appearance satisfaction (the Appearance Evaluation subscale score of the MBSRQ) was not significant $(r=.11, p=.16)$. Additionally, there was no significant correlation between frequency of electronic game play and participants’ association of muscularity with positive traits (SMAQ Positive Attribute of Muscularity subscale score), $(r=-.02, p=.85)$ or their motivation to become more muscular (SMAQ Drive for Muscularity subscale score), $(r=-.06, p$ $=.38)$.

\section{Hypothesis Two}

The correlation between the age of commencement of electronic game play and selfreport ratings of overall appearance satisfaction (the Appearance Evaluation subscale of the MBSRQ) was not significant $(r=-.08, p=.35)$. Additionally, there was no significant correlation between the age of commencement of electronic game play and participants’ association of muscularity with positive character traits (SMAQ-Positive Attribute of Muscularity subscale score) $(r=.07, p=.37)$ or participants’ motivation to become more muscular (SMAQ Drive for Muscularity subscale score), $(r=.07, p=.34)$.

\section{Hypothesis Three}

There was a significant negative correlation between the degree to which a participant compares himself physically to the characters in video games and his score on the Appearance Evaluation factor of the MBSRQ, $r=-.187, p<.05$. The frequency of this comparison was determined by the participant's response to an item from the demographic questionnaire. Thus, the more frequent the physical comparisons to a game character, the less satisfied players are 
with their own physical appearance. Conversely, the more satisfied players are with their own physical appearance, the less often they will compare their bodies to those depicted for game characters. Additionally, there was a significant relationship between the degree of physical comparison to game characters and the Positive Attributes of Muscularity factor score of the SMAQ, $r=.21, p<.05$. Thus, the more positively a participant associates desirable traits (masculinity, partner attractiveness, maturity, etc.) with muscularity, the more frequently he makes physical comparisons to a game character.

\section{Hypothesis Four}

To determine if any mean differences exist for any particular genre of electronic game across scores on the MBSRQ Appearance Evaluation factor, the SMAQ Positive Attributes of Muscularity subscale score and the SMAQ Drive for Muscularity subscale score, a Multivariate Analyses of Variance (MANOVA) was conducted. No significant main effect of genre was found for any of the subscale scores.

\section{Exploratory Multiple Regressions}

Two multiple regression analyses using simultaneous entry were conducted to test the overarching hypothesis that certain aspects of electronic game play predict one's assessment of his attractiveness and muscularity. The first criterion variable was the Appearance Evaluation subscale of the MBSRQ with the predictor variables weekly electronic game playing frequency, age of commencement, and frequency of physical trait comparisons to game characters. The regression equation was not significant. The second criterion variable was the SMAQ Positive Attributes of Muscularity subscale score with predictor variables weekly frequency, age of commencement, and degree of physical trait comparisons to game characters. Again, the 
regression equation was not significant. Thus, the three electronic game play predictor variables did not predict scores on the Appearance Evaluation or Positive Attributes of Muscularity subscales.

An additional multiple regression analysis using simultaneous entry was conducted to determine the extent to which physical comparison to game characters predicts scores on the Appearance Evaluation subscale of the MBSRQ. The regression equation was significant, $R^{2}=$ .03 , adjusted $R^{2}=.03, F(1)=6.73, p<.05$, indicating that the degree of physical comparison in which a player engages during electronic game play is predictive of the extent to which he is satisfied or dissatisfied with his own appearance. 
Table 1

Mean Ratings of Attractiveness and Standard Deviations for Women from BMI Categories by Players of Electronic Games

Mean Rating Standard Deviation

Underweight

Normal Weight

Overweight

Obese
$3.33^{*}$

6.95*

$4.51^{*}$

$3.28 *$
1.82

1.15

1.33

1.39

$N=126$

Note. * indicates significant mean difference at .05 level found between at least one other BMI classification 
Table 2

Mean Ratings of Attractiveness for Women from BMI Categories by Players of Different Genres

\section{Players Only $(n=126)$}

\begin{tabular}{lcccc} 
Genre & Underweight & Normal Weight & Overweight & Obese \\
\hline Fantasy Role-Playing & $3.93^{*}$ & 7.08 & 4.75 & 3.36 \\
First Person Shooter & $2.68^{*}$ & $6.67^{*}$ & 4.26 & 3.19 \\
Action & $3.83^{*}$ & 7.03 & 4.33 & $2.98^{*}$ \\
Sports & 3.40 & $6.50^{*}$ & $4.17 *$ & 3.20 \\
Racing & $2.43^{*}$ & $7.52^{*}$ & 4.48 & $2.79^{*}$ \\
Fighting & 3.17 & 7.39 & $4.94^{*}$ & $4.17^{*}$ \\
Miscellaneous & $4.50^{*}$ & $7.67^{*}$ & 4.79 & 3.25 \\
& & & & \\
\hline
\end{tabular}

Note. ${ }^{*}$ indicates significant mean difference at .05 level found between at least one other genre 
Table 3

Mean Selection of Most Attractive Breast Size from the Breast/Chest Rating Scale by Players of Different Genres

Genre $\quad \underline{\text { Total Sample }(n=219)} \quad \underline{\text { Players Only }(n=126)}$

$\begin{array}{llc}\text { Fantasy Role-Playing } & 3.77^{*} & 3.74^{*} \\ \text { First Person Shooter } & 3.83^{*} & 3.83^{*} \\ \text { Action } & 3.39^{*} & 3.39^{*} \\ \text { Sports } & 4.05^{*} & 4.06^{*} \\ \text { Racing } & 4.39^{*} & 4.31^{*} \\ \text { Fighting } & 3.57^{*} & 3.67 \\ \text { Miscellaneous } & 3.91 & 3.78 \\ & & \\ & \end{array}$


Table 4

Correlations between Attributions of Desirable Personality Characteristics for Women within Each BMI Classification and Frequency of Play

BMI Classification $\quad r$

Underweight $\quad-.02$

Normal Weight

.09

Overweight

.04

Obese

.004

$N=219, p<.01$ 
Table 5

Percentages of Players who Indicated Majority of Play Within Each Genre and Mean Hours of Play Reported Over a Three-Day Period for Each Genre

\begin{tabular}{lcc} 
Genre & Percent & Mean Hours \\
\hline Fantasy Role-Playing & 32.0 & 8.2 \\
First Person Shooter & 22.0 & 6.7 \\
Action & 18.7 & 4.8 \\
Sports & 9.3 & 3.0 \\
Miscellaneous & 7.3 & 5.0 \\
Racing & 6.0 & 3.1 \\
Fighting & 4.7 & 4.4 \\
\hline $\begin{array}{l}\text { N = 126 } \\
\text { Note. Participants who indicated that they do not currently play electronic games were not included. }\end{array}$ &
\end{tabular}




\section{CHAPTER FOUR: DISCUSSION}

The results primarily contradict the hypotheses that attitudes toward attractiveness are influenced by various aspects (frequency, age of commencement, game genre) of electronic game play, unlike research examining the influence of electronic games on attitudes towards violence. The results of this study also contradict, to some extent, the body of literature illuminating the impact of the images that individuals see in the media on perceptions of others' attractiveness. For instance, the contrast effect purports that after viewing particularly attractive figures, individuals will find more typically attractive figures less attractive than they would have had they not viewed the attractive figures (Kenrick \& Gutierres, 1980). Generally, previous research suggests that the media plays a large role in the development of certain cognitions and behaviors (Agliata \& Tantleff-Dunn, 2004; Thompson \& Stice, 2001; Dittmar, Halliwell, \& Ive, 2003; Groesz, Levine, \& Murnen, 2002; Anderson \& Bushman, 2001). The results of the current study lend support to the notion that media images may impact appraisals of one's own attractiveness, but also suggest that electronic game play, unlike other forms of media, may not exert a particularly strong influence on men’s appraisals of women’s attractiveness although electronic games are infamous for depicting males as hyper masculine with exaggerated muscularity and women as unrealistically proportioned with a thin waist and large breasts and hips (Scharrer, 2004; Dietz, 1998).

A major contradiction to the theoretical basis of this study, established from previous research within the realm of violence and electronic gaming, is the positive correlation between frequency of play and ratings of normal weight women, as well as the significantly higher ratings 
of normal weight women than underweight women. The significant correlation between the number of hours spent playing electronic games and higher appraisals of attractiveness for women of normal BMI and WHR contradicts the idea that playing electronic games establishes an unrealistic body ideal and standard of attractiveness for women. In fact, quite the opposite is suggested in that men who play more electronic games find normally proportioned women to be more attractive than men who do not play video games as frequently. Additionally, there is no significant linear relationship between selection of a "most attractive” breast size and frequency of play, further disputing the hypothesis that men who play electronic games with unrealistic depictions of women more often will reliably find larger breasts to be more attractive. The analyses revealed few significant findings related to any impact electronic game play has for appraisals of women outside of the normal range, either under or overweight. Electronic game play does not appear to influence players’ perceptions of attractiveness for underweight women, whose thinness is closer to that depicted among female game characters (although their proportions are not similar), or for overweight women, who appear much larger than female game characters.

However, there is some evidence that suggests that the genre of electronic game most frequently played is related to differential ratings of female figures, indicating that, in line with previous research, there are some aspects of game play that impact appraisals of attractiveness for others. Significant mean differences in ratings of attractiveness for women of certain BMI classifications by players of different genres provide preliminary evidence for the idea that the particular type of electronic media exposure an individual experiences may affect what type of body he finds most attractive. For instance, participants who endorsed playing fantasy role- 
playing games (a genre known to exhibit particularly unrealistic and hyper-sexualized figures) most frequently rated underweight women as significantly more attractive than did players of racing and first person shooter games. Players of action games also rated underweight women as significantly more attractive while players of fighting games rated obese women significantly higher than players of other genres, indicating that, to some extent, the particular types of images that exist within certain game genres may influence males' appraisals of female attractiveness.

Further evidence for the impact of genre on appraisals of attractiveness are the significant differences in the selection of a "most attractive" breast size from the Breast/Chest rating scale between players of particular genres. Players of action games selected a significantly smaller ideal breast than players of other genres which, considered in the context of their higher ratings of underweight women, indicates that players of certain genres may show preferences for a particular female silhouette (thinner and less busty). However, fantasy role-playing gamers did not on the whole select a larger "most attractive" breast than gamers from any other genre. In fact, players of racing games chose a significantly larger ideal breast size than players of other genres of electronic games.

However, the significance of these genre differences must be investigated with a clear and systematic understanding of the particular content unique to each of these genres. A content analysis aimed at identifying the particular differences in the visual stimuli inherent to each genre will be important for further analyzing the trends suggested by the findings of this study. For instance, it would be important to investigate why differences in appraisals of attractiveness might exist for players of fighting games, wherein the character is almost exclusively human and male, fighting with weapons against some kind of enemy where strength (achieved through 
muscularity and artillery) and fantasy role-playing games, wherein the character can be either human or non-human and creativity, skill and foresight are valued over physical strength.

Furthermore, when contemplating differences that appear between genres of game, it is very important to consider the circular logic that accompanies any findings. It is difficult to know, without the benefit of random assignment, whether players of particular genres show differences in ratings as a result of repeated exposure to the particular images employed by games within that genre or whether particular individuals with pre-established notions and values are drawn to certain genres above others. Due to this confound, ascertaining the exact mechanism affecting genre differences is difficult. This idea is further explored in the limitations section of this discussion.

Although there were some interesting findings related to the association between electronic game play and the appraisals men make about women, the results examining the influence of electronic game play on participants' appraisals of their own attractiveness were more limited. However, the results of the study do indicate that a certain aspect of electronic game play is related to men's body image: the frequency of player-character physical comparison during game play. The results of the analyses examining player-character comparison invoke the social comparison theory, which posits that people are constantly involved in physical comparison that inevitably impacts self-esteem (Festinger, 1954). The results of the current study suggest confirmatory evidence for social comparison theory in that there was a significant relationship between the frequency of physical comparison to game characters and appraisals of one's own attractiveness as well as the association of more positive traits with muscularity. Additionally, there is an inverse relationship between frequency of 
comparison and the Appearance Evaluation subscale of the MBSRQ, such that the more comparison during game play, the lower the player's appraisal of his own attractiveness and vice versa. Furthermore, high frequency of physical comparison is related to a stronger association of muscularity with positive traits like masculinity, maturity, and attractiveness to prospective partners. This finding carries with it the implication proposed by the social comparison theory, that degree of player-character comparison may be part of the mechanism exerting influence on player cognitions and informing players about what is desirable and attractive for a male physique.

Further evidence for the idea that physical comparison with game characters detrimentally influences players’ appearance satisfaction is provided by the multiple regression analysis examining the influence of the frequency of appearance comparison to game characters on body satisfaction, which indicated a significant predictive relationship. Thus, the degree to which players compare their physiques to that of the characters in the electronic game they most often play can potentially reveal their own level of body image satisfaction or dissatisfaction. The results of this analysis provide preliminary information about the negative impact of playercharacter comparison on males' perceptions of their own bodies and how strongly they associate muscularity with several desirable personality characteristics. The results suggest that although variables related to the game play itself (frequency, age of commencement, and genre) do not appear to impact self-appraisals of attractiveness, player-character comparison is potentially detrimental to the development of a positive and healthy body image, which potentially could result in psychological distress. 
Beyond the main hypotheses of the study, several interesting findings demonstrate the degree to which electronic game play appears to be an entrenched part of the current collegeaged male culture. The mean age for commencement of electronic game play was between seven and eight years of age. Now in their twenties, participants self-reported playing electronic games frequently, with $92.7 \%$ of participants reporting they had played electronic games within the last month and $62.1 \%$ reporting they played electronic games within 24 hours of participating in the study.

As part of the demographic questionnaire, participants were asked to estimate the approximate number of hours they currently spend playing electronic games (video or computer) per week. As previously discussed, the sample mean of self- reported approximations was 3.07 hours per week. However, when asked to recall and record their electronic game play time over the previous three days with the use of the timeline follow-back procedure, the mean number of hours for this significantly smaller time frame was 4.17, which resulted in a daily average of 1.39 hours and a weekly average of 9.73 hours. Obviously, there is a large discrepancy in the selfreported weekly frequency and the weekly frequency calculated from the timeline follow-back procedure. These conflicting numbers may warrant further investigation into perceived versus actual time spent on electronic gaming. Additionally, $8.5 \%$ of the sample reported playing over 15 hours of electronic games in the three-day periods measured with the timeline follow-back procedure. Assuming game play frequency remains consistent throughout the week, these players are spending an average of 35 hours per week on electronic games. However, there is a confound to this measure in that depending on the date the participant took the survey, the play is being tracked over differential time periods. For instance, if a participant completed the survey 
on a Monday and reported game play for the previous three days, that period would include a weekend, which could potentially result in an exaggerated game play total. However, it is difficult to implement a strategy to account for all possible time period confounds to this measurement strategy, besides asking participants to recount their game play over an entire week which would be a very time-consuming task.

It is also worth noting trends in the genres of games played by the participants. As previously discussed, each individual who completed the three-day timeline follow-back procedure had his gaming habits examined and was assigned a preferred genre based on frequency of play of a game within that genre. Genre popularity in order from most popular to least popular was as follows: fantasy/role playing, first person shooter, action, sports, miscellaneous, and fighting (see Table 5 for exact percentages and average hours of play for the three-day reporting period).

Despite several indications that the frequency and genre of electronic game play influence males’ appraisals of attractiveness in females and that player-character physical comparison influences male body image, the evidence for the influence of this media on appraisals of physical attractiveness is not nearly as conclusive as that found for other types of media (television or print media). A possible explanation for these limited findings may be in part accounted for by the uniquely interactive nature of electronic media, which typically involves players achieving some sort of objective that may overshadow the physical features of the characters. Perhaps, players' cognitive resources are allocated more exclusively to the game objective rather than the characters that merely exist to provide a visual context for that objective. It appears that when there is active player-character physical comparison than 
cognitive energy can be devoted to the appearance of the game characters, thereby activating social comparison that potentially results in body dissatisfaction. Furthermore, the results of this study do not align conclusively with those examining the impact of violence in electronic games on the real world behavior of players. Perhaps the explanation may again involve the interactivity of the media, wherein the violence in the games is a means to achieving the objective; it is an active component that clearly results in success or failure. However, the players' schemas for physical appearance may not be influenced to the same degree as their aggressive behavior because that schema is not essential to success in the game and thus, is not

reinforced or rehearsed throughout play. Thus, the interactive nature of this media may moderate the effect of the game imagery on players' assessments of physical attractiveness.

Although not as robust as previous literature examining the impact of media on body image, the results of this study indicate that certain aspects of electronic gaming impact men's body image. The clinical implications of body image dissatisfaction are numerous and anything contributing to this dissatisfaction should be recognized and neutralized if possible. The results do not indicate conclusively that playing electronic games causes players to find women more or less attractive but do reveal that there are several signs that aspects of this powerful interactive media exert influence on what men consider desirable in the opposite sex.

\section{$\underline{\text { Limitations }}$}

There are several limitations to the study that warrant closer consideration. First, the range of photographs included was somewhat limited. A larger selection that more accurately spans the BMI classifications would be more effective for gauging participants' perceptions of attractiveness and limiting within-classification differences. However, no particular woman was 
rated significantly differently from other women within her BMI classification which was important to ascertain in order to rule out the possibility that the rating of a particular body was an outlier that could potentially influence the results. In addition, including photographs of women with proportions more similar to those featured in electronic gaming media would be helpful in ascertaining more directly players' perceptions of these idealized proportions. However, it is difficult to find these idealized shapes in reality, hence the theoretical basis of this study.

Another limitation of the study was the actual length of the survey, which might have discouraged would-be participants from taking the survey or completing it fully. Several wouldbe participants discontinued participation without fully completing the measures. Although all participants took the survey online, perhaps having them complete the measures in a paper form would have made it more difficult to discontinue participation. However, it was decided that utilizing the electronic survey format would be more appealing for participants familiar and comfortable with computer-based interaction.

Another limitation inherent to the nature of a correlational study is the inability to conclude what came first: appraisals about self and others reinforced by the games or playing games that encourage particular appraisals about self and others. Evidently, there is a great deal of physical comparison occurring between players and the characters within the games but it is difficult to know if players may be drawn to games that cater to their particular fantasy or, as proposed by the hypotheses, may be influenced by the comparison that occurs during game play.

Perhaps the greatest question raised by the study is whether or not any conclusions about the results could be made for game players given that their game playing behavior, for instance 
their choice of genre, may be the result of inherent personality characteristics and preferences for the type of stimuli employed by that game. As previously discussed, it is difficult to know whether a player chooses to play a certain genre because of his own internal motivation toward such genre-specific stimuli or whether he plays that game primarily because of other external factors. It is important to take into consideration that the electronic gaming market caters to an individual's preferences for particular stimuli, whether it be games involving gunning down bad guys, watching shapely girls play volleyball in bikinis, or devising an elaborate plan to overthrow a demon warlord's goblin army.

\section{$\underline{\text { Future Directions }}$}

Due to the limitations discussed above, the logical progression of this research would be to extend it to an experimental setting wherein participants, both game players and non players, could be randomly assigned to play either games depicting female and male figures of particularly sexualized and exaggerated proportions or games featuring human characters whose physiques do not emphasize sexuality or call attention to their physical attractiveness. In this manner, the type of media itself could be isolated from the well-established game play preferences a person may have already acquired over time. Therefore, the exact mechanism in question, the influence of electronic gaming variables on appraisals of attractiveness, could be examined and manipulated more directly.

Overall, the results are at once a relief and a puzzle given that the theoretical basis for this investigation was based on previous findings that media exerts a powerful influence on the schemas that observers of that media utilize to evaluate attractiveness and appropriate behavior (Anderson \& Bushman, 2001; Anderson et al., 2003). Within the realm of violence and video 
games, research has generally concluded that repeated play of games featuring particular stimuli impacts players' behavior and cognitions. The results of this particular study do not align with those suggested by previous research that forms the theoretical foundation for both the sociocultural theory of body image and the purported contrast effect, which emphasize the impact that viewing attractive images has on appraisals of the attractiveness for oneself and others. Although the results indicate that the frequency of game play and the particular genre played most often may be related to differences in ratings of attractiveness of women, generally the influence does not appear to align in any predictable way with the conclusions of previous studies on the impact of media on appraisals of attractiveness. It is comforting to believe that, as the results of this study suggest, playing electronic games may not specifically impact the body image of those men who currently play or who have been involved in play over the long term. A possible explanation for these limited findings may be in part accounted for by the uniquely interactive nature of electronic media, which typically involves players in some sort of quest that may take the focus off of the physical features of the characters. However, the frequency of physical comparisons between the player and the characters in the games does appear to be related to appearance satisfaction. The results of this study underscore the need for more research examining the impact that this increasingly prevalent form of media can potentially have on body image and standards of attractiveness as well as other facets of human behavior and cognition. 


\section{APPENDIX A: DEMOGRAPHIC QUESTIONNAIRE WITH TIMELINE}

FOLLOW-BACK CALENDAR 
Throughout the completion of this survey, please try to answer the questions to the best of your ability. However, if you feel uncomfortable responding to any of the particular questions, please skip it and proceed to the next question. Additionally, please remember that you are free to discontinue the survey at any time without penalty if you feel that the material is upsetting you.

- Age

Demographic Questionnaire

- Race (please circle):

Caucasian/White African American/Black Hispanic/Latino Asian/Pacific Islander Biracial Other

- I consider myself to be:
Heterosexual
Gay
Bisexual

- Major

- Please write your approximate GPA:

- Are you currently dating someone or in a committed relationship (please circle your answer)?

Yes No

- Please circle the approximate number of hours you currently spend playing electronic games (video or computer) per week:

None 2-3 hours $\quad 4-7$ hours $\quad 8-10$ hours $\quad 11-16$ hours $\quad 16$ or more hours

- Please circle the approximate number of hours you currently spend watching television per week:

None $\quad$ 2-3 hours $\quad$ 4-7 hours $\quad 8-10$ hours $\quad 11-16$ hours $\quad 16$ or more hours

- Please circle the approximate number of hours you currently spend reading pornographic magazines (i.e., Playboy, Hustler) per week:

None 2-3 hours $\quad$ 4-7 hours $\quad$ 8-10 hours $\quad 11-16$ hours 16 or more hours

- Please circle the approximate number of hours you currently spend reading male-oriented magazines (i.e., Maxim, FHM) per week: 
None 2-3 hours $\quad$ 4-7 hours $\quad 8-10$ hours $\quad 11-16$ hours $\quad 16$ or more hours

- Do you own a video game console?

\section{YES NO RENT BORROW}

- If you answered yes, please indicate the type(s) of console:

- At what grade level did you start playing electronic games?

- What was the title of the first electronic game you became familiar with when you first started playing?

- Please circle the last time you played a video or computer game:
A. Within the past 24 hours
B. A week ago
C. A month ago
D. A year ago
E. Several years ago
F. Never played electronic games

- Please write the approximate age at which you started playing electronic games:

2. If you currently play video or computer games, please write the name of the video or computer game you play most often:

Please circle your answers to the following questions.

3. When I play electronic games, I imagine myself to be the character I am playing. Never Rarely Sometimes Often Always

4. When I am in a stressful situation in a game, I can feel my heart start pumping. Never Rarely Sometimes Often Always 
5. I play electronic games when I am in a good mood.

Never Rarely Sometimes Often Always

6. I play electronic games when I am angry or frustrated.

Never Rarely Sometimes Often Always

7. When I lose or am unable to achieve whatever I am hoping to in the game, I remain disappointed throughout the day.

Never Rarely $\quad$ Sometimes Often Always

8. When I can't play on a particular day, I am disappointed.

Never Rarely Sometimes Often Always

9. While I am playing the game, the situation feels very real to me.

Never Rarely Sometimes Often Always

10. My friends play electronic games with me.

$\begin{array}{llll}\text { Never } & \text { Rarely } & \text { Sometimes } & \text { Often }\end{array}$

11. I play electronic games when I am bored.

$\begin{array}{llll}\text { Never } & \text { Rarely } & \text { Sometimes } & \text { Often }\end{array}$

12. I compare my appearance to the physical appearance of the characters I play.

$\begin{array}{llll}\text { Never } & \text { Rarely } & \text { Sometimes } & \text { Often }\end{array}$

13. I like to play electronic games more than I like to go to out.

Never Rarely Sometimes Often Always

14. I play electronic games when I am lonely.

$\begin{array}{llll}\text { Never } & \text { Rarely } & \text { Sometimes } & \text { Often }\end{array}$

15. While I am playing, I can’t think about anything else.

Never Rarely Sometimes Often Always 
16. Playing electronic games helps me to relieve my stress.

$\begin{array}{llll}\text { Never } & \text { Rarely Sometimes } & \text { Often Always }\end{array}$


The following questions will ask you to recall your game play activity of the last week in detail, starting with yesterday and going back seven days. In order to help you more accurately recall your activity, please take out your planner or look at a calendar. Please try to complete the questions as accurately as you can but if you cannot remember exactly, please make your best estimate. However, if you have no information to enter (if you have not played electronic games in any particular day or days of the past week), simply check the box that indicates that you did NOT play on that day and move to the next day.

Would you consider this past week a typical week for you in terms of electronic game play?

YES NO

\section{YESTERDAY:}

Check here if no games played this day and move to the next page.

Title of First Game Played:

Approx. Start Time: a.m./p.m.

Approx End Time: a.m./p.m.

Total Time played:

hours Minutes

Check here if no other games were played this day and proceed to the next page.

Title of Second Game Played:

Is this the same game as previously played?

YES NO

Approx. Start Time: a.m./p.m.

Approx End Time: a.m./p.m.

Total Time played:

hours Minutes

Check here if no other games were played this day and proceed to the next page.

Title of Third Game Played:

Is this the same game as previously played?

\section{YES NO}

Approx. Start Time:

a.m./p.m.

Approx End Time: a.m./p.m.

Total Time played:

hours Minutes 
Were more games played during this day? Please circle Yes or No then continue to the next page.

YES NO

\section{TWO DAYS AGO:}

Check here ___ if no games played this day and move to the next page.

Title of First Game Played:

Approx. Start Time:

a.m./p.m.

Approx End Time: a.m./p.m.

Total Time played:

hours Minutes

Check here if no other games were played this day and proceed to the next page.

Title of Second Game Played:

Is this the same game as previously played?

YES NO

Approx. Start Time: a.m./p.m.

Approx End Time: a.m./p.m.

Total Time played:

hours Minutes

Check here if no other games were played this day and proceed to the next page.

Title of Third Game Played:

Is this the same game as previously played?

YES NO

Approx. Start Time: a.m./p.m.

Approx End Time: a.m./p.m.

Total Time played: hours Minutes 
Were more games played during this day? Please circle Yes or No then continue to the next page.

YES NO

\section{THREE DAYS AGO:}

Check here if no games played this day and move to the next page.

Title of First Game Played:

Approx. Start Time: a.m./p.m.

Approx End Time: a.m./p.m.

Total Time played:

hours Minutes

Check here if no other games were played this day and proceed to the next page.

Title of Second Game Played:

Is this the same game as previously played?

YES NO

Approx. Start Time: a.m./p.m.

Approx End Time: a.m./p.m.

Total Time played:

hours Minutes

Check here if no other games were played this day and proceed to the next page.

Title of Third Game Played:

Is this the same game as previously played?

YES NO

Approx. Start Time: a.m./p.m.

Approx End Time: a.m./p.m.

Total Time played: 
hours ___ Minutes

Were more games played during this day? Please circle Yes or No then continue to the next page.

YES NO 


\section{APPENDIX B: FIGURE RATING SCALE}


The figures below are accompanied by numbers from $1-9$. You will be asked to select a figure to respond to certain questions. You may use ratings that fall between numbers (for instance, if you wanted a figure between 4 and 5, you could pick 4.2, 4.7, etc.).

1. Write the number of the female figure you find most attractive.

2. Write the number of the female figure that you think is preferred by most women.

3. Write the number of the female figure that you think is preferred by most men.
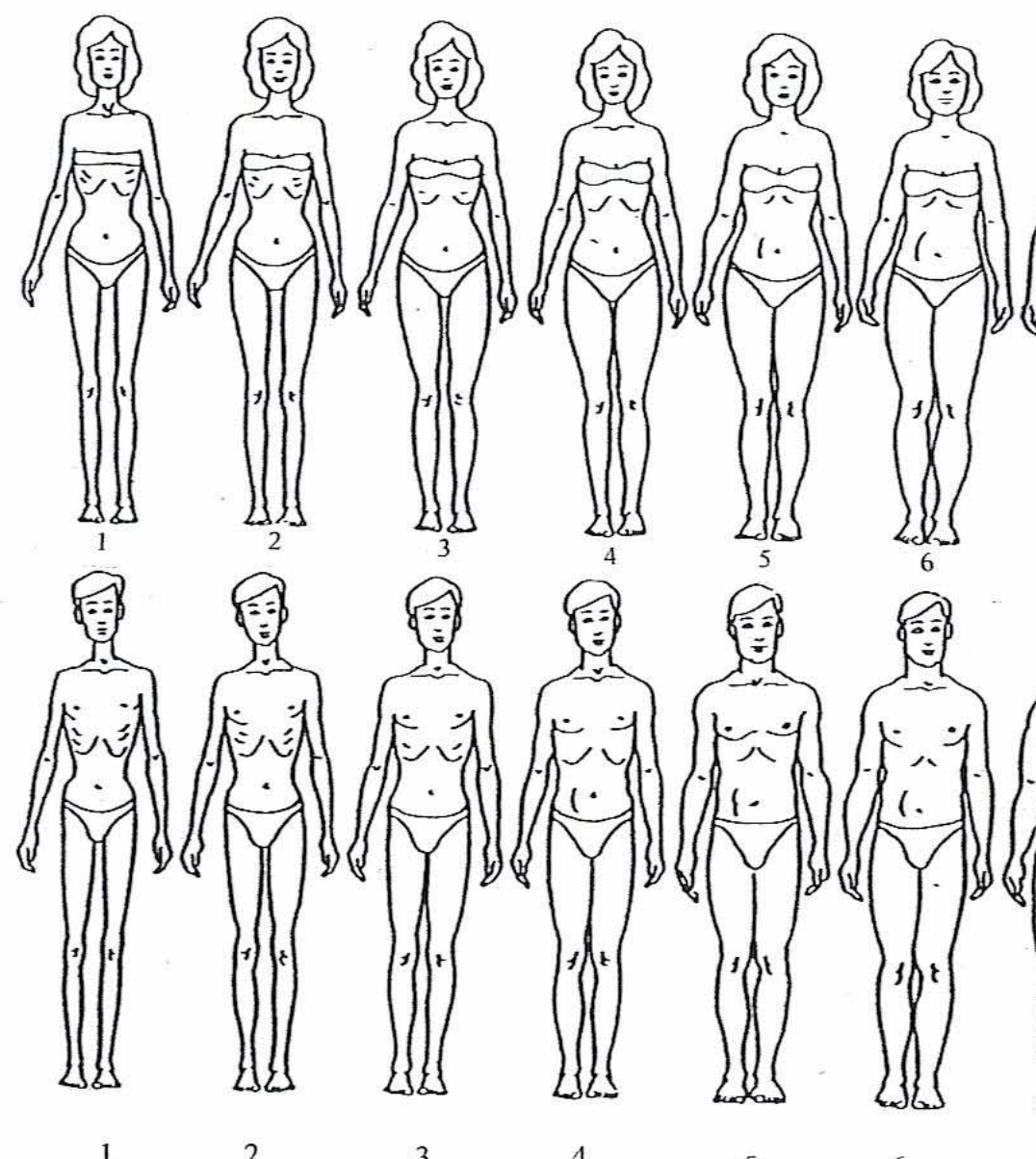

2

3

4

5

6

4. Write the number of the male figure you think is ideal.

5. Write the number of the male figure you think is preferred by most women.

6. Write the number of the male figure you think is preferred by most men. 


\section{APPENDIX C: BREAST/CHEST RATING SCALE}


The figures below are accompanied by numbers from $1-9$. You will be asked to select a figure to respond to certain questions. You may use ratings that fall between numbers (for instance, if you wanted a figure between 4 and 5 , you could pick 4.2 , 4.7 , etc.).

7. Choose the breast size you find most attractive.

8. Choose the breast size you think most women prefer.

9. Choose the breast size you think is preferred by most men.

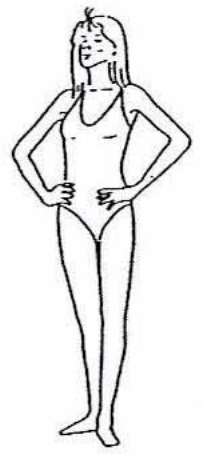

1

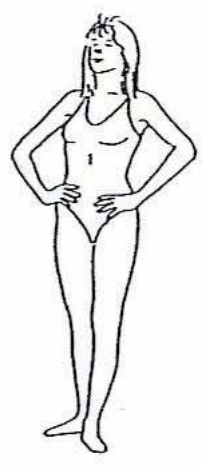

2

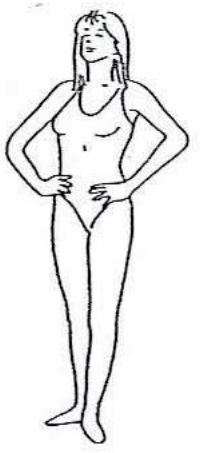

3

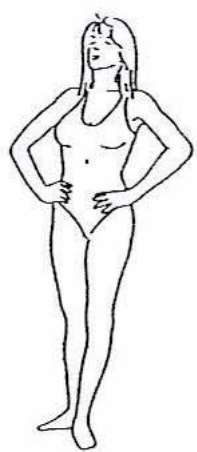

4

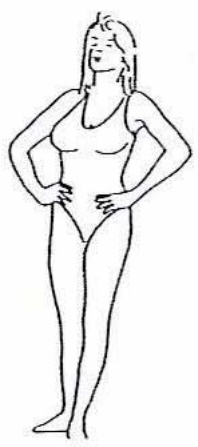

5

10. Choose the chest size that you find ideal.

11. Choose the chest size that you think most women prefer.

12. Choose the chest size you think is preferred by most men.

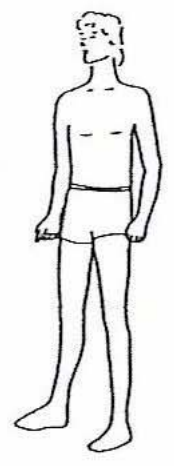

1

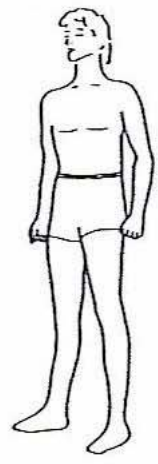

2

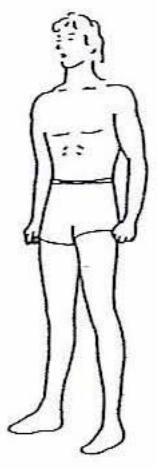

3

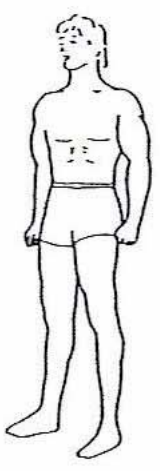

4

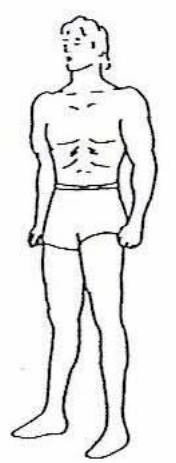

5 


\section{APPENDIX D: PHOTOGRAPHS OF COLLEGE-AGED FEMALES}

AND PERSONALITY ATTRIBUTIONS 
Please rate the attractiveness of this person on a scale of 1 to $10, \mathbf{1}$ being the least attractive and 10 being the most attractive.

Sometimes we think we can tell a lot about a person by the way they look. In the absence of all other information, please estimate some of the characteristics of the figure on this page.

How intelligent is this person? (Please circle your choice)

$$
\text { not at all somewhat above average extremely }
$$

How successful is this person?

$$
\text { not at all somewhat above average extremely }
$$

How confident is this person?

$$
\text { not at all somewhat above average extremely }
$$

How sexually active is this person?

$$
\text { not at all somewhat above average extremely }
$$

How athletic is this person?

$$
\text { not at all somewhat above average extremely }
$$

How popular is this person?

not at all somewhat above average extremely

How lonely is this person?

not at all somewhat above average extremely

How depressed is this person?

not at all somewhat above average extremely

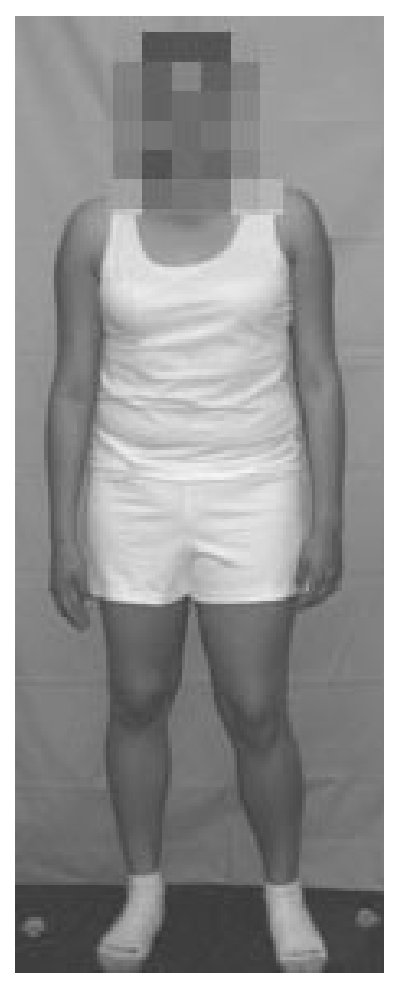


Please rate the attractiveness of this person on a scale of 1 to $10, \mathbf{1}$ being the least attractive and 10 being the most attractive.

Sometimes we think we can tell a lot about a person by the way they look. In the absence of all other information, please estimate some of the characteristics of the figure on this page.

How intelligent is this person?

$$
\text { not at all somewhat above average extremely }
$$

How successful is this person?

$$
\text { not at all somewhat above average extremely }
$$

How confident is this person?

$$
\text { not at all somewhat above average extremely }
$$

How sexually active is this person?

$$
\text { not at all somewhat above average extremely }
$$

How athletic is this person?

$$
\text { not at all somewhat above average extremely }
$$

How popular is this person?

$$
\text { not at all somewhat above average extremely }
$$

How lonely is this person?

not at all somewhat above average extremely

How depressed is this person?

not at all somewhat above average extremely

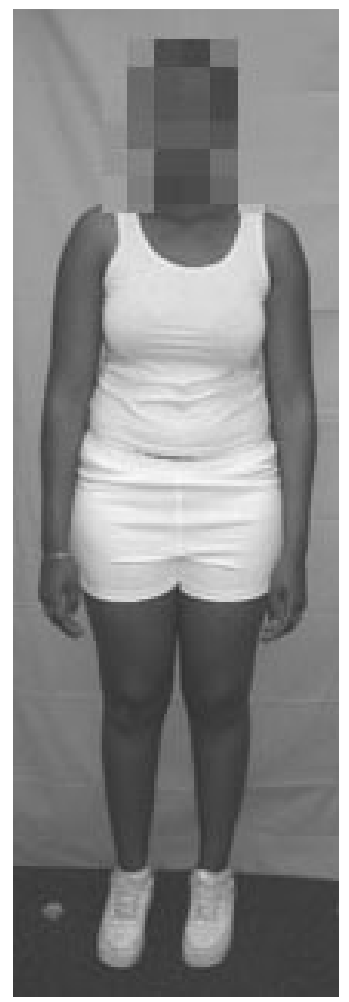


Please rate the attractiveness of this person on a scale of 1 to 10,1 being the least attractive and 10 being the most attractive.

Sometimes we think we can tell a lot about a person by the way they look. In the absence of all other information, please estimate some of the characteristics of the figure on this page.

How intelligent is this person? (Please circle your choice) not at all somewhat above average

extremely

How successful is this person?

not at all somewhat above average extremely

How confident is this person?

not at all somewhat above average

extremely

How sexually active is this person?

not at all somewhat above average extremely

How athletic is this person?

not at all somewhat above average extremely

How popular is this person?

not at all somewhat above average extremely

How lonely is this person?

not at all somewhat above average extremely

How depressed is this person?

not at all somewhat above average extremely

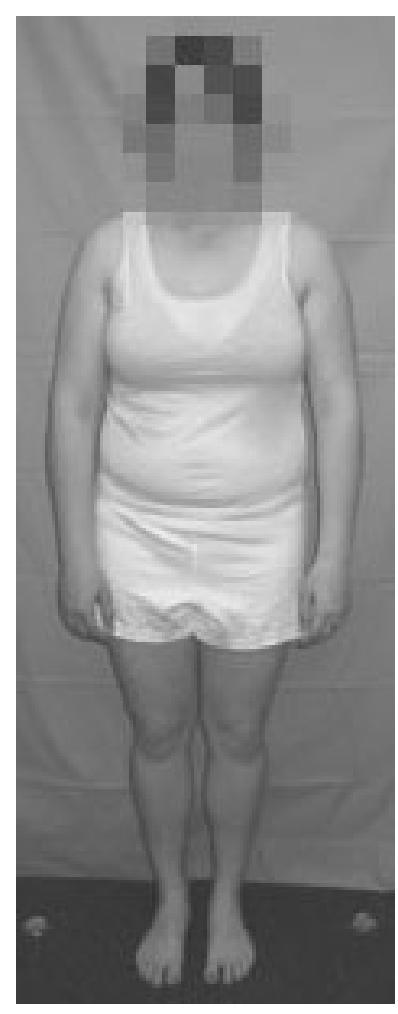


Please rate the attractiveness of this person on a scale of 1 to $10, \mathbf{1}$ being the least attractive and 10 being the most attractive.

Sometimes we think we can tell a lot about a person by the way they look. In the absence of all other information, please estimate some of the characteristics of the figure on this page.

How intelligent is this person?

$$
\text { not at all somewhat above average extremely }
$$

How successful is this person?

$$
\text { not at all somewhat above average extremely }
$$

How confident is this person?

$$
\text { not at all somewhat above average extremely }
$$

How sexually active is this person?

$$
\text { not at all somewhat above average extremely }
$$

How athletic is this person?

$$
\text { not at all somewhat above average extremely }
$$

How popular is this person?

$$
\text { not at all somewhat above average extremely }
$$

How lonely is this person?

$$
\text { not at all somewhat above average extremely }
$$

How depressed is this person?

not at all somewhat above average extremely

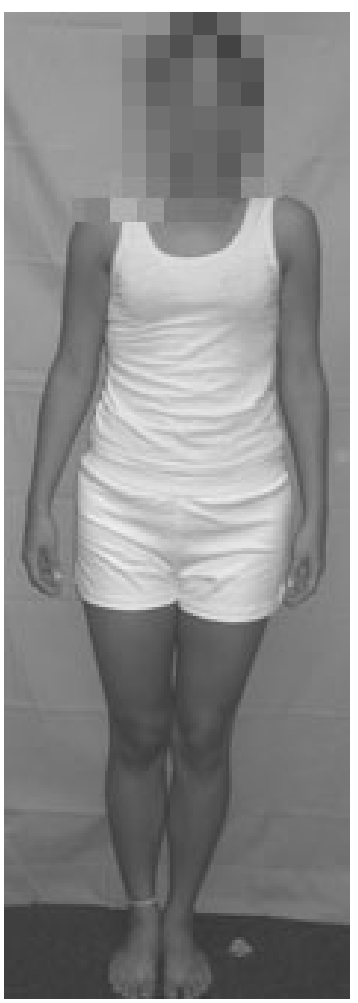


Please rate the attractiveness of this person on a scale of 1 to 10,1 being the least attractive and 10 being the most attractive.

Sometimes we think we can tell a lot about a person by the way they look. In the absence of all other information, please estimate some of the characteristics of the figure on this page.

How intelligent is this person? (Please circle your choice) not at all somewhat above average extremely

How successful is this person? not at all somewhat above average

extremely

How confident is this person? not at all somewhat above average

extremely

How sexually active is this person?

not at all somewhat above average extremely

How athletic is this person? not at all somewhat above average

extremely How popular is this person? not at all somewhat above average extremely How lonely is this person? not at all somewhat above average extremely How depressed is this person? not at all somewhat above average

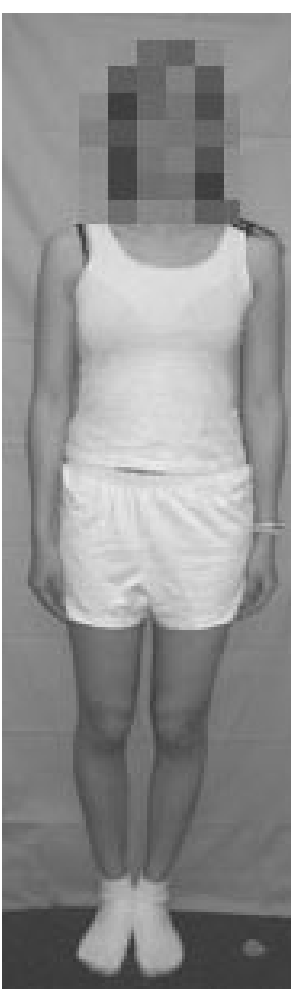


Please rate the attractiveness of this person on a scale of 1 to $10, \mathbf{1}$ being the least attractive and 10 being the most attractive.

Sometimes we think we can tell a lot about a person by the way they look. In the absence of all other information, please estimate some of the characteristics of the figure on this page.

How intelligent is this person?

$$
\text { not at all somewhat above average extremely }
$$

How successful is this person?

$$
\text { not at all somewhat above average extremely }
$$

How confident is this person?

$$
\text { not at all somewhat above average extremely }
$$

How sexually active is this person?

$$
\text { not at all somewhat above average extremely }
$$

How athletic is this person?

$$
\text { not at all somewhat above average extremely }
$$

How popular is this person?

not at all somewhat above average extremely

How lonely is this person?

not at all somewhat above average extremely

How depressed is this person?

not at all somewhat above average extremely

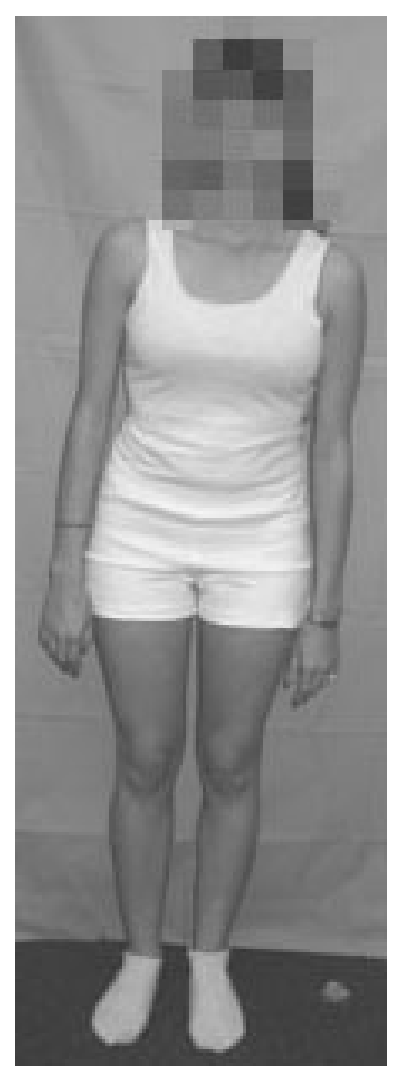


Please rate the attractiveness of this person on a scale of 1 to 10,1 being the least attractive and 10 being the most attractive.

Sometimes we think we can tell a lot about a person by the way they look. In the absence of all other information, please estimate some of the characteristics of the figure on this page.

How intelligent is this person? (Please circle your choice) not at all somewhat above average extremely

How successful is this person?

not at all somewhat above average extremely

How confident is this person?

not at all somewhat above average extremely

How sexually active is this person?

not at all somewhat above average extremely

How athletic is this person?

not at all somewhat above average extremely

How popular is this person?

not at all somewhat above average extremely

How lonely is this person?

not at all somewhat above average extremely

How depressed is this person?

not at all somewhat above average extremely

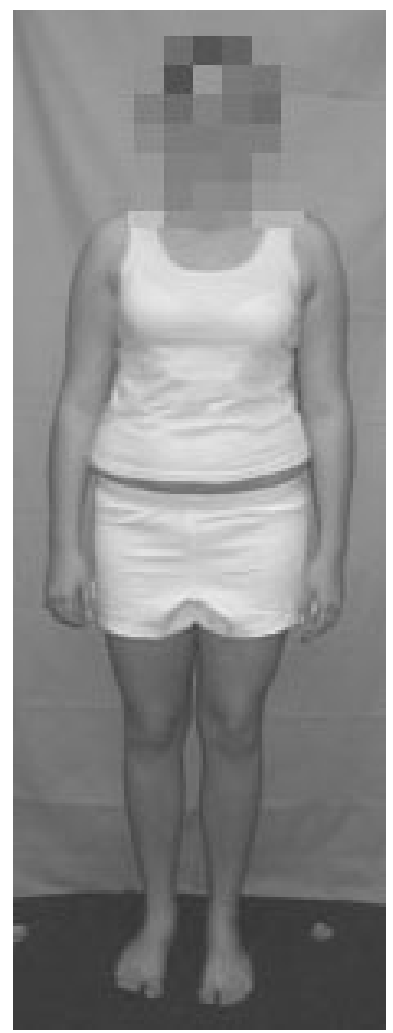


Please rate the attractiveness of this person on a scale of 1 to $10, \mathbf{1}$ being the least attractive and 10 being the most attractive.

Sometimes we think we can tell a lot about a person by the way they look. In the absence of all other information, please estimate some of the characteristics of the figure on this page.

How intelligent is this person?

not at all somewhat above average extremely

How successful is this person?

not at all somewhat above average extremely

How confident is this person?

not at all somewhat above average extremely

How sexually active is this person?

not at all somewhat above average extremely

How athletic is this person?

not at all somewhat above average extremely

How popular is this person?

not at all somewhat above average extremely

How lonely is this person?

not at all somewhat above average extremely

How depressed is this person?

not at all somewhat above average extremely

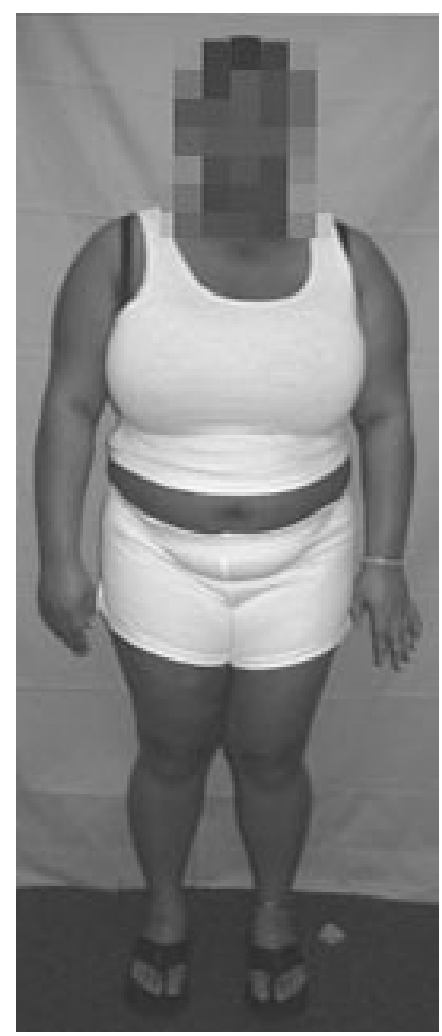


Please rate the attractiveness of this person on a scale of 1 to 10,1 being the least attractive and 10 being the most attractive.

Sometimes we think we can tell a lot about a person by the way they look. In the absence of all other information, please estimate some of the characteristics of the figure on this page.

How intelligent is this person? (Please circle your choice) not at all somewhat above average extremely

How successful is this person?

not at all somewhat above average extremely

How confident is this person?

not at all somewhat above average extremely

How sexually active is this person?

not at all somewhat above average extremely

How athletic is this person?

not at all somewhat above average extremely

How popular is this person?

not at all somewhat above average extremely

How lonely is this person?

not at all somewhat above average extremely

How depressed is this person?

not at all somewhat above average extremely

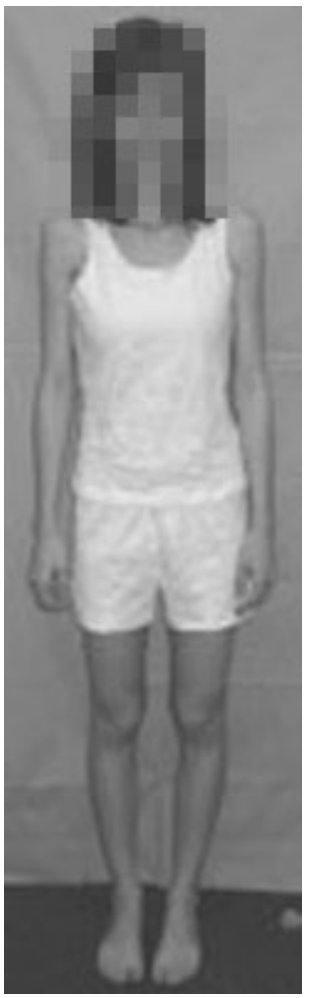


Please rate the attractiveness of this person on a scale of 1 to 10, 1 being the least attractive and 10 being the most attractive.

Sometimes we think we can tell a lot about a person by the way they look. In the absence of all other information, please estimate some of the characteristics of the figure on this page.

How intelligent is this person?

not at all somewhat above average extremely

How successful is this person?

not at all somewhat above average extremely

How confident is this person?

not at all somewhat above average extremely

How sexually active is this person?

not at all somewhat above average extremely

How athletic is this person?

not at all somewhat above average extremely

How popular is this person?

not at all somewhat above average extremely

How lonely is this person?

not at all somewhat above average extremely

How depressed is this person?

not at all somewhat above average extremely

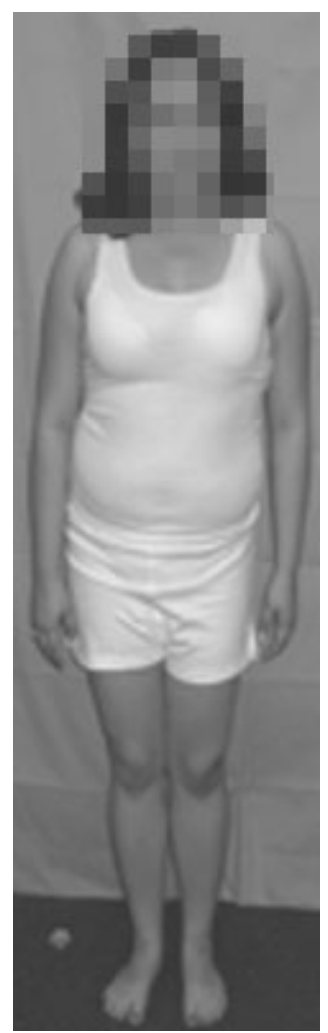




\section{APPENDIX E: SWANSEA MUSCULARITY ATTITUDES QUESTIONNAIRE}


15. I feel less of a man when I have small muscles than when I have large muscles.

16. It is important to me to be more, rather than less, muscular.

17. Being muscular gives me confidence

18. I feel that when I have small muscles I do not look as good as when I have

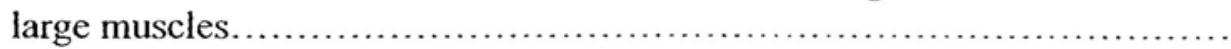

19. I would prefer to be more rather than less muscular ..........................

20. I feel more of a mature man when I have large muscles. 


\section{APPENDIX F: MULTIDIMENSIONAL BODY-SELF RELATIONS QUESTIONNAIRE}




\section{THE MBSRQ}

\section{INSTRUCTIONS--PLEASE READ CAREFULLY}

The following pages contain a series of statements about how people might think, feel, or behave. You are asked to indicate the extent to which each statement pertains to you personally.

Your answers to the items in the questionnaire are anonymous, so please do not write your name on any of the materials. In order to complete the questionnaire, read each statement carefully and decide how much it pertains to you personally. Using a scale like the one below, indicate your answer by entering it to the left of the number of the statement.

\begin{tabular}{ccccc}
1 & 2 & 3 & 4 & 5 \\
\hline $\begin{array}{c}\text { Definitely } \\
\text { Disagree }\end{array}$ & $\begin{array}{c}\text { Mostly } \\
\text { Disagree }\end{array}$ & $\begin{array}{c}\text { Neither } \\
\text { Agree Nor } \\
\text { Disagree }\end{array}$ & $\begin{array}{c}\text { Mostly } \\
\text { Agree }\end{array}$ & $\begin{array}{c}\text { Definitely } \\
\text { Agree }\end{array}$
\end{tabular}

EXAMPLE :

I am usually in a good mood.

In the blank space, enter a 1 if you definitely disagree with the statement; a 2 if you mostly disagree; a 3 if you neither agree nor disagree; a 4 if you mostly agree; or enter a 5 if you definitely agree with the statement.

There are no right or wrong answers. Just give the answer that is most accurate for you. Remember, your responses are anonymous, so please be completely honest and answer all items.

(The duplication and use of the MBSRQ permitted by

Thomas F. Cash, Ph.D., Department of Psychology,

old Dominion University, Norfolk, VA 23529) 


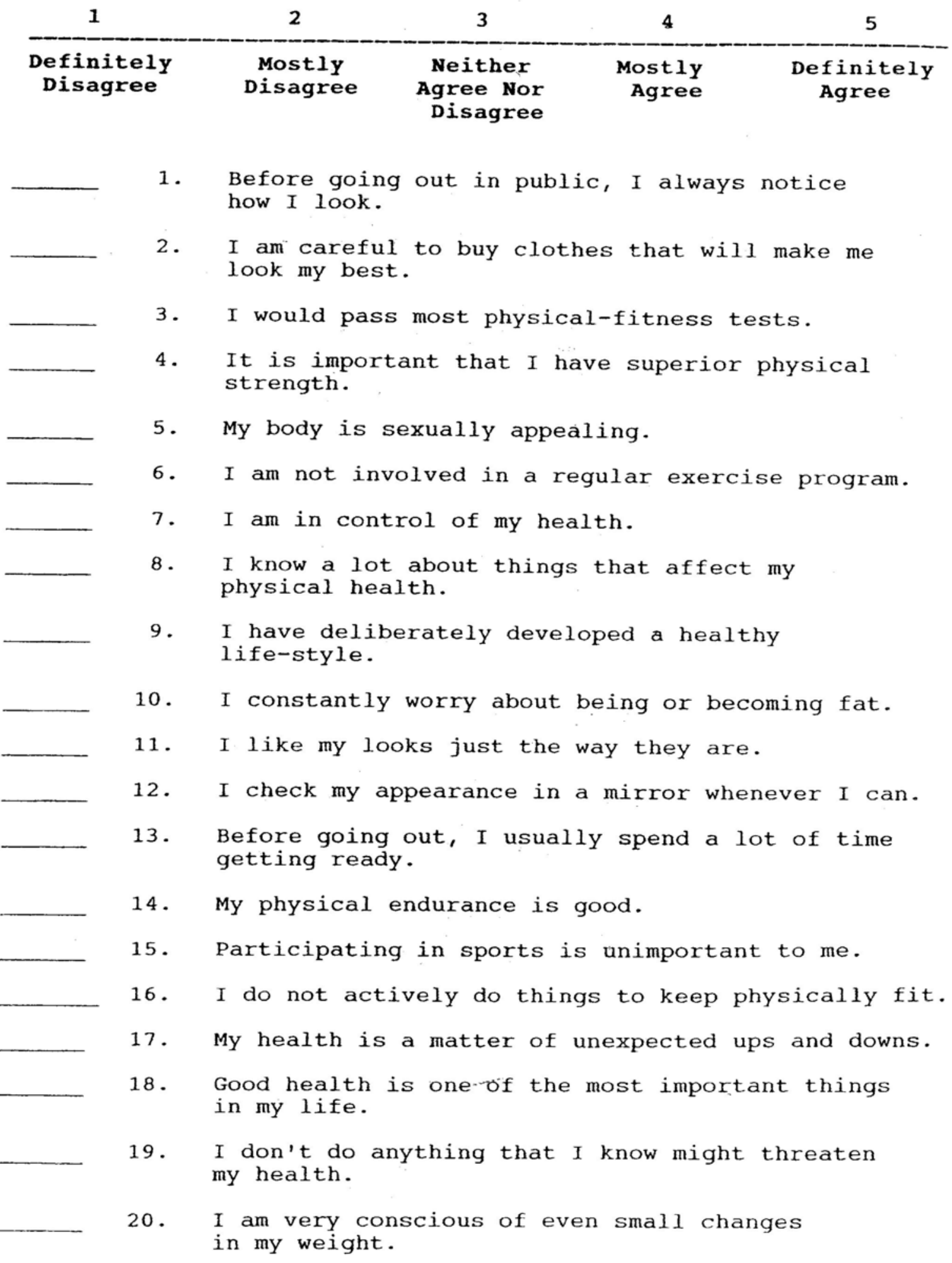




\begin{tabular}{ccccc}
1 & 2 & 3 & 4 & 5 \\
\hline $\begin{array}{c}\text { Definitely } \\
\text { Disagree }\end{array}$ & $\begin{array}{c}\text { Mostly } \\
\text { Disagree }\end{array}$ & $\begin{array}{c}\text { Neither } \\
\text { Agree Nor } \\
\text { Disagree }\end{array}$ & $\begin{array}{c}\text { Mostly } \\
\text { Agree }\end{array}$ & $\begin{array}{c}\text { Definitely } \\
\text { Agree }\end{array}$
\end{tabular}

21. Most people would consider me good-looking.

22. It is important that $I$ always look good.

23. I use very few grooming products.

24. I easily learn physical skills.

25. Being physically fit is not a strong priority in my life.

26. I do things to increase my physical strength.

27. I am seldom physically ill.

28. I take my health for granted.

29. I often read books and magazines that pertain to health.

30. I like the way I look without my clothes on.

31. I am self-conscious if my grooming isn't right.

32. I usually wear whatever is handy without caring how it looks.

33. I do poorly in physical sports or games.

34. I seldom think about my athletic skills.

35. I work to improve my physical stamina.

36. From day to day, I never know how my body will feel.

37. If I am sick, I don't pay much attention to my symptoms.

38. I make no special effort to eat a balanced and nutritious diet.

39. I like the way my clothes fit me.

40. I don't care what people think about my appearance. 


\begin{tabular}{ccccc}
1 & 2 & 3 & 4 & 5 \\
\hline $\begin{array}{c}\text { Definitely } \\
\text { Disagree }\end{array}$ & $\begin{array}{c}\text { Mostly } \\
\text { Disagree }\end{array}$ & $\begin{array}{c}\text { Neither } \\
\text { Agree Nor } \\
\text { Disagree }\end{array}$ & $\begin{array}{c}\text { Mostly } \\
\text { Agree }\end{array}$ & $\begin{array}{c}\text { Definitely } \\
\text { Agree }\end{array}$
\end{tabular}

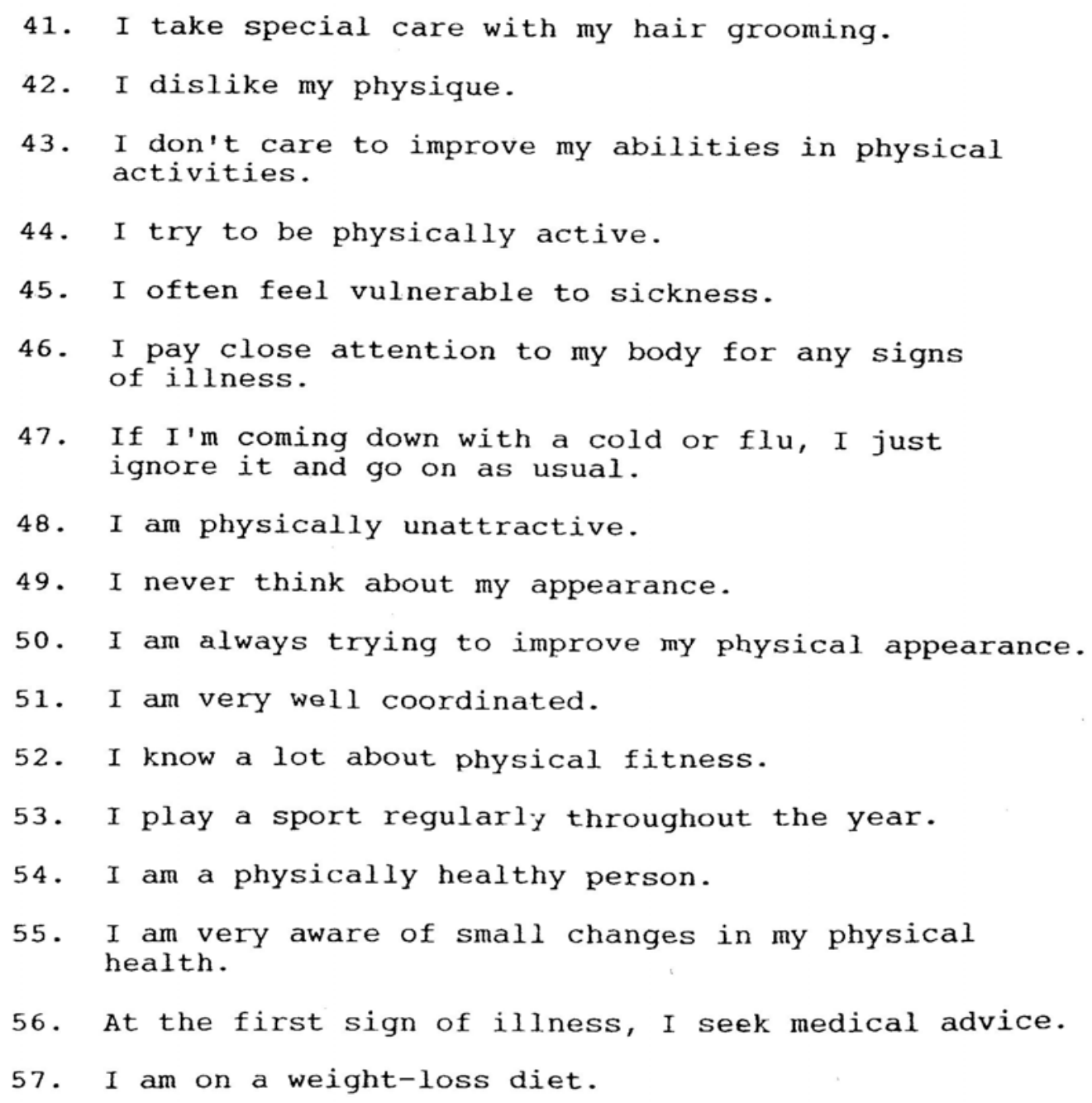

For the remainder of the items use the response scale given with the item, and enter your answer in the space beside the item.

$$
\text { (continued on the next page) }
$$


58. I have tried to lose weight by fasting or going on crash diets.
1. Never
2. Rarely
3. Sometimes
4. Often
5. Very Often

59. I think I am:

1. Very Underweight

2. Somewhat Underweight

3. Normal Weight

4. Somewhat overweight

5. Very Overweight

60. From looking at me, most other people would think I am:

1. Very Underweight

I comewhat Underweight

3. Normal Weiaht

4. Somewh $=t$ Overweight

5. Very Overweight

61-69. Use this 1 to 5 scale to indicate how satisfied you are

with each of the following areas or aspects of your body:

\begin{tabular}{ccccc}
1 & 2 & 3 & 4 & 5 \\
\hline $\begin{array}{c}\text { Very } \\
\text { Dissatisfied }\end{array}$ & $\begin{array}{c}\text { Mostly } \\
\text { Dissatisfied }\end{array}$ & $\begin{array}{c}\text { Neither } \\
\text { Satisfied } \\
\text { Nor } \\
\text { Dissatisfied }\end{array}$ & $\begin{array}{c}\text { Mostly } \\
\text { Satisfied }\end{array}$ & $\begin{array}{c}\text { Very } \\
\text { Satisfied }\end{array}$
\end{tabular}

61. Face (facial features, complexion)

62. Hair (color, thickness, texture)

63. Lower torso (buttocks, hips, thighs, legs)

64. Mid torso (waist, stomach)

65. Upper torso (chest or breasts, shoulders, arms)

66. Muscle tone

67. Weight

68. Height

69. Overall appearance 


\section{APPENDIX G: SOCIOCULTURAL ATTITUDES TOWARDS}

APPEARANCE QUESTIONNAIRE- VERSION 3 


\section{SATAQ-3}

Please read each of the following items carefully and indicate the number that best reflects your agreement with each statement.

Definitely Disagree $=\mathbf{1}$

Mostly Disagree $=2$

Neither Agree Nor Disagree = 3

Mostly Agree $=4$

Definitely Agree $=5$

1.TV programs are an important source of information about fashion and "being attractive.

2.I've felt pressure from TV or Magazines to lose weight.

3. I do not care if my body looks like the body of people who are on TV.

4. I compare my body to the bodies of people who are on TV.

5. TV commercials are an important source of information about fashion and "being attractive."

6. I do not feel pressure from TV or magazines to look attractive.

7. I would like my body to look like the models who appear in magazines.

8. I compare my appearance to the appearance of TV and movie stars.

9. Music videos on TV are not an important source of information about fashion and "being attractive.

10. I've felt pressure from TV and magazines to be thin.

11. I would like my body to look like the people who are in movies.

12. I do not compare my body to the bodies of people who appear in magazines.

13. Magazine articles are not and important source of information about fashion and "being attractive.”

14. I've felt pressure from TV or magazines to have a perfect body.

15. I wish I looked like the models in music videos.

16. I compare my appearance to the appearance of people in magazines. 
17. Magazine advertisements are an important source of information about fashion and "being attractive.”

18. I’ve felt pressure from TV or magazines to diet.

19. I do not wish to look as athletic as the people in magazines.

20. I compare my body to that of people in "good shape."

21. Pictures in magazines are an important source of information about fashion and "being attractive."

22. I've felt pressure from TV or magazines to exercise.

23. I wish I looked as athletic as sports stars.

24. I compare my body to that of people who are athletic.

25. Movies are an important source of information about fashion and "being attractive.”

26. I've felt pressure from TV or magazines to change my appearance.

27. I do not try to look like the people on TV.

28. Movie stars are not an important source of information about fashion and "being attractive."

29. Famous people are an important source of information about fashion and "being attractive."

30. I try to look like sports athletes. 


\section{LIST OF REFERENCES}

Agliata, D. \& Tantleff-Dunn, S. (2004). The impact of media exposure on males’ body images. Journal of Social and Clinical Psychology, 23, 7-22.

Anderson, C., Berkowitz, L., Donnerstein, E., Huesmann, L.R., Johnson, J.D., Linz, D., Malamuth, N.M., \& Wartella, E. (2003). The influence of media violence in youth. Psychological Science in the Public Interest, 4, 81-110.

Anderson, C. \& Bushman, B. (2001). Effects of violent video games on aggressive behavior, aggressive cognition, aggressive affect, physiological arousal, and prosocial behavior: a meta-analytic review of the scientific literature. Psychological Science, 12, 353-359.

Anderson, C. \& Dill, K.E. (2000). Video games and aggressive thoughts, feelings, and behavior in the laboratory and in life. Journal of Personality and Social Psychology, 78, 772790.

Beasley, B. \& Collins Standley, T. (2002). Shirts vs. skins: Clothing as an indicator of gender role stereotyping in video games. Mass Communication \& Society, 5(3), 1520-5436.

Bjorntorp, P. (1991). Adipose tissue distribution and function. International Journal of Obesity, 15, 67-81.

Brase, G.L. \& Walker, G. (2004). Male sexual strategies modify ratings of female models with specific waist-to-hip ratios. Human Nature, 15(2), 209-224.

Buchman, D.D. \& Funk, J.B. (1996). Video and computer games in the ‘90s: Children’s time commitment and game preference. Children Today, 24,12-16. 
Bushman, B.J. \& Huesmann, L.R.(2001). Effects of televised violence on aggression. In D.G. Singer \& J.L. Singer (Eds.), Handbook of Children and the media (pp 223-254). Thousand Oaks, CA: Sage.

Cash, T.F. (1997). The body image workbook: An 8-step program for learning to like your looks. Oakland, CA: New Harbinger.

Cash, T.F., Winstead, B.W., \& Janda, L.H. (1986). The great American shape-up: Body image survey report. Psychology Today, 20, 30-37.

Cash, T.F., Winstead, B.W., \& Janda, L.H. (1985). Your body, yourself: A Psychology Today reader survey. Psychology Today, 19, 22-26.

Dickinson, A. (2000). Video Playground. Time, 19, 98.

Dietz, T.L. (1998). An examination of violence and gender role portrayals in video games: Implications for gender socialization and aggressive behavior. Sex Roles, 38, 425-442.

Dittmar, H., Halliwell, E., \& Ive, S. (2005). Does Barbie make girls want to be thin? The effect of experimental exposure to images of dolls on the body image of 5-8-year old girls. Developmental Psychology, 42, 283-292.

Donnerstein, E., Slaby, R.G., \& Eron, L.D.(1994). The mass media and youth aggression. In: L.D. Eron, J.H. Gentry, \& P. Schlegel (Eds.), Reason to hope: A psychological perspective on violence and youth (pp. 219-250). Washington, DC: American Psychological Association.

Dorr, A., \& Rabin, B.E. (1995). Parents, children, and television. In: M. Bornstein (Ed.), Handbook of parenting, (vol. 4, pp. 323-351). Mahwah, NJ: Erlbaum. 
Edwards, S. \& Launder, C. (2000). Investigating muscularity concerns in male body image:

Development of the Swansea muscularity attitudes questionnaire. International Journal of Eating Disorders, 28, 120-124.

Festinger, L. (1954). A theory of social comparison processes. Human Relations, 7(2) 117-140.

Gentile, D.A. \& Walsh, D.A. (2002). A normative study of family media habits. Journal of Applied Developmental Psychology, 23, 157-178.

Groesz, L.M., Levine, M.P., \& Murnen, S.K. (2002). The effect of experimental presentation of thin media images on body satisfaction: A meta-analytic review. International Journal of Eating Disorders, 31, 1-16.

Heinberg, L.J., Thompson, J.K., \& Stormer, S. (1995). Development and validation of the Sociocultural Attitudes Towards Appearance Questionnaire. International Journal of Eating Disorders, 179(1), 81-89.

Huston, A.C., Donnerstein, E., Fairchild, H., Feshbach, N.D., Katz, P.A., Murray, J.P., Rubinstein, E.A., Wilcox, B.L., \& Zuckerman, D.M. (1992). Big world, small screen: The role of television in American Society. Lincoln, NE: University of Nebraska Press.

Ivory, J. D. (2006). Still a man’s game: Gender representation in online reviews of video games. Journal of Mass Communication \& Society, 9, 103-114.

Jenkin, H. (2000). Art form for the digital age. Technology Review, 103(5), 117-120.

Kenrick, D.T. \& Gutierres, S.E. (1980). Contrast effects and judgments of physical attractiveness: When beauty becomes a social problem. Journal of Personality \& Social Psychology, 38, 131-140. 
Kenrick, D.T., Gutierres, S.E., \& Goldberg, L.L. (1989). Influence of popular erotica on judgements of strangers and mates. Journal of Experimental Social Psychology, 25, 159-167.

Kestenbaum, G. \& Weinstein, L.(1985). Personality, psychopathology, and developmental issues in male adolescent video game use. Journal of the American Academy of Child Psychiatry, 24, 329-333.

Pew Internet and American Life Project. (2003, July). Let the games begin: Gaming technology and entertainment among college students. Washington, DC: Steve Jones.

Rideout, V.G., Roberts, D.F., \& Foehr, U.G. (2005). Generation M: Media in the lives of 8-18 year-olds. Menlo Park, CA: Kaiser Family Foundation.

Robinson, T.N. (1999). Reducing children's television viewing to prevent obesity. Journal of the American Medical Association, 282,1561-1567.

Scharrer, E. (2004) Virtual violence: Gender and Aggression in video game advertisements. Journal of Mass Communication \& Society, 7, 393-412.

Singh, D. \& Luis, S. (1995). Ethnic and gender consensus for the effect of waist-to-hip ratio on judgment of women’s attractiveness and desirability for relationships. Ethology and Sociobiology, 16, 484-507.

Singh, D. (1993a). Adaptive significance of female physical attractiveness: Role of waist-to-hip ratio. Journal of Personality and Social Psychology, 65, 293-307.

Singh, D. (1993b). Body shape and women's attractiveness: The critical role of Waist-to-hip ratio. Human Nature, 4, 297-321. 
Singh, D. (1994a). Ideal female body shape: The role of body weight and waist-to-hip ratio. International Journal of Eating Disorders, 16, 283-288.

Singh, D. (1994b). Is thin really beautiful and good? Relationship between waist-to-hip ratio (WHR) and female attractiveness. Personal and Individual Differences, 16, 123-132.

Sobell, L.C. \& Sobell, M.B. (1992). Timeline follow-back: A technique for assessing selfreported alcohol consumption. In R.Z. Litten \& J.P. Allen (Eds.). Measuring alcohol consumption: Psychosocial and biological methods (pp.41-72). Totowa, NJ: Humana Press.

Stice, E., Schupak-Neuberg, E., Shaw, H.E., \& Stein, R.I. (1994). Relation of media exposure to eating disorder symptomology: An examination of mediating mechanisms. Journal of Abnormal Psychology, 103, 836-840.

Tantleff-Dunn, S. (2002). Biggest isn’t always best: The effect of breast size on perceptions of women. Journal of Applied Social Psychology, 32, 2253 -2265.

Thompson, J.K. \& Altabe, M.N. (1991). Psychometric qualities of the Figure Rating Scale. International Journal of Eating Disorders, 10, 615-619.

Thompson, J.K., Heinberg, L.J., Altabe, M., \& Tantleff-Dunn, S. (1999). Exacting beauty: Theory, assessment, and treatment of body image disturbance. Washington, DC: American Psychological Association.

Thompson, J.K. \& Stice, E. (2001). Thin-ideal internalization: Mounting evidence for a new risk factor for body-image disturbance and eating pathology. Current Directions in Psychological Science, 10, 181-183. 
Thompson, J.K. \& Tantleff, S. (1992). Female and male ratings of upper torso: Actual, ideal, and stereotypical conceptions. Journal of Social Behavior and Personality, 7, 345-354.

Thompson, J.K., van den Berg, P., Roehrig, M., Guarda, A.S., \& Heinberg, L.J. (2004). The Sociocultural Attitudes Towards Appearance Scale-3 (SATAQ-3): Development and validation. International Journal of Eating Disorders, 35, 293-304.

Tovee, M.J., Maisey, D.S., Emery, J.L., \& Cornelissen, P.L. (1999). Visual cues to female physical attractiveness. Proceedings of the Royal Society London B, 266, 211-2118

Tovee, M.J., Reinhardt, S., Emery, J.L., \& Cornelissen, P.L. (1998). Optimal BMI and maximum sexual attractiveness. The Lancet, 352, 548.

Wass, P., Waldenstrom, U., Rossner, S., \& Hellberg, D. (1997). An android body fat distribution in females impairs the pregnancy rate of in-vitro fertilization-embryo transfer. Human Reproduction, 12, 2057-2060.

World Health Organization (1997). Preventing and Managing the Global Epidemic of Obesity. Report of the World Health Organization Consultation of Obesity, Geneva. 